\title{
EFFECT OF DIAMOND-LIKE CARBON DOPED WITH CHROMIUM ON CELL DIFFERENTIATION, IMMUNE ACTIVATION AND APOPTOSIS
}

\author{
M. Travnickova ${ }^{1}$, M. Vandrovcova ${ }^{1}$, E. Filova ${ }^{1, *}$, M. Steinerova ${ }^{1}$, J. Rackova $^{1}$, T. Kocourek ${ }^{2,3}$, J. Bartova $^{4}$, \\ T. Suchy ${ }^{5}$, M. Zaloudkova ${ }^{5}$, M. Jelinek ${ }^{2,3}$ and L. Bacakova ${ }^{1}$
}

${ }^{1}$ Department of Biomaterials and Tissue Engineering, Institute of Physiology of the Czech Academy of Sciences, Videnska 1083, 14220 Prague 4, Czech Republic

2 Institute of Physics of the Czech Academy of Sciences, Na Slovance 2, 18221 Prague 8, Czech Republic

${ }^{3}$ Faculty of Biomedical Engineering, Czech Technical University in Prague, nam. Sitna 3105, 27201 Kladno, Czech Republic

${ }^{4}$ Institute of Dental Medicine, General University Hospital in Prague, Karlovo nam. 554/32, 12808 Prague, Czech Republic

${ }^{5}$ Department of Composites and Carbon Materials, Institute of Rock Structure and Mechanics, Czech Academy of Sciences, V Holesovickach 94/41, 182 09, Prague 8, Czech Republic

\begin{abstract}
Diamond-like carbon (DLC) is a biocompatible material that has many potential biomedical applications, including in orthopaedics. DLC layers doped with $\mathrm{Cr}$ at atomic percent (at.\%) of 0, 0.9, 1.8, 7.3, and 7.7 at.\% were evaluated with reference to their osteoinductivity with human bone marrow mesenchymal stromal cells (hMSCs), immune activation potential with RAW 264.7 macrophage-like cells, and their effect on apoptosis in Saos-2 human osteoblast-like cells and neonatal human dermal fibroblasts (NHDFs). At mRNA level, hMSCs on DLC doped with 0.9 and 7.7 at.\% of Cr reached higher maximum values of both RUNX2 and alkaline phosphatase. An earlier onset of mRNA production of type I collagen and osteocalcin was also observed on these samples; they also supported the production of both type I collagen and osteocalcin. RAW 264.7 macrophages were screened using a RayBio ${ }^{\mathrm{TM}}$ Human Cytokine Array for cytokine production. 10 cytokines were at a concentration more than $2 \times$ as high as the concentration of a positive control, but the values for the DLC samples were only moderately higher than the values on glass. NHDF cells, but not Saos-2 cells, had a higher expression of pro-apoptotic markers Bax and Bim and a lower expression of anti-apoptotic factor BCL-XL in proportion to the $\mathrm{Cr}$ content. Increased apoptosis was also proven by annexin $\mathrm{V}$ staining. These results show that a $\mathrm{Cr}$-doped DLC layer with a lower $\mathrm{Cr}$ content can act as an osteoinductive material with relatively low immunogenicity, but that a higher $\mathrm{Cr}$ content can induce cell apoptosis.
\end{abstract}

Keywords: Chromium, biocompatibility, mesenchymal stromal cells, apoptosis, osteogenic differentiation, macrophages.

*Address for correspondence: Elena Filova, PhD, Department of Biomaterials and Tissue Engineering, Institute of Physiology of the Czech Academy of Sciences, Videnska 1083, 14220 Prague 4, Czech Republic. Telephone number: +420 296443742 Email: elena.filova@fgu.cas.cz

Copyright policy: This article is distributed in accordance with Creative Commons Attribution Licence (http://creativecommons.org/licenses/by-sa/4.0/).

\section{Introduction}

Nowadays, many patients suffer from degenerative or traumatic diseases of bones and joints. Bone tissue engineering aims to modify current implants to improve their osseointegration into the bone tissue. Osseointegration of bone implants is a complex process affected by many factors, e.g. the physical and chemical properties of the material surface, and the mechanical properties and the behaviour of an implant in its biological environment. The physical and chemical properties of an implant include its wettability, surface energy, surface roughness, electrical conductivity, corrosion resistance, release of ions from the material surface, and many more factors. The osseointegration and long-term stability of the implant is also affected by the mechanical properties of the prostheses, e.g. Young's modulus, and wear resistance. The interaction of the implant with its biological environment is influenced by the biocompatibility, osteoconductivity and osteoinductivity of the implant, the immune response 
to the implant, and other factors at the site of a patient's implant (Reichert et al., 2016).

Several metals and alloys are widely used in large joint replacements, e.g. 316L stainless steels, cobaltbased alloys, e.g. CoCrMo, and Ti-based alloys, e.g. Ti-6Al-4V (Chen and Thouas, 2015). The mechanical properties of these alloys are not ideal. The Young's modulus of 316L stainless steel is $200 \mathrm{GPa}$ and the modulus of CoCrMo is $240 \mathrm{GPa}$, while the modulus of cortical bone is in the range from 10 to $30 \mathrm{GPa}$. Tibased alloys brought an improvement, as the Young's modulus of Ti-6Al-4V is $110 \mathrm{GPa}$, and the modulus of newly-developed $\beta$-Ti alloys, e.g. TiNb, is as low as 65 - 93 GPa. A mismatch in mechanical properties causes increased bone resorption around the implant site after some time, and subsequently the need for replacement of the implant (Chen and Thouas, 2015). Another problem with the usage of metallic alloys is the release of $\mathrm{Co}, \mathrm{Mo}, \mathrm{Cr}, \mathrm{Ti}, \mathrm{Al}, \mathrm{V}$ or $\mathrm{Ni}$ particles and ions into the adjacent tissues or into the blood circulation, and the potential toxicity of the alloys (Long and Rack, 1998; Rogers et al., 1997; Tower, 2010; Vyskocil and Viau, 1999; Wataha et al., 2001; Yokel, 2000). In order to improve biocompatibility, to minimise toxicity and to prolong the functioning of implants, they can be coated with a suitable impermeable layer, such as Diamond-like carbon (DLC).

DLC is a material with high hardness, a low frictional coefficient, high wear and corrosion resistance, chemical inertness, high electrical resistivity, infrared-transparency, a high refractive index, and excellent smoothness (Alanazi et al., 2000a; Roy and Lee, 2007). All these properties rate DLC materials among good biomaterials for applications in orthopaedic and cardiovascular implants, as well as in contact lenses and dentistry (Roy and Lee, 2007). DLC shows good biocompatibility in both in vitro and in vivo studies (Alanazi et al., 2000b; Allen et al., 2001; Liao et al., 2016). Fibroblasts, osteoblasts and macrophages can grow on the DLC film surface without any inflammation or cytotoxicity (Roy and Lee, 2007).

The disadvantage of a pure DLC layer without any dopants is its weak adhesion to biomedical alloys, which can result in peeling off in time (Wei et al., 1999). The wear resistance and the adhesion strength of a DLC layer to a biomedical alloy can be improved by pre-treating the alloy, e.g. by plasma (Ozeki et al., 2010), by engaging an appropriate interlayer (Kopova et al., 2019), or by doping a pure DLC layer with various metal ions, e.g. Ti (Wang et al., 2007) or with Cr (Dai et al., 2010).

$\mathrm{Cr}$ is a crucial trace element for human metabolic pathways. $\mathrm{Cr}$ can appear mainly in trivalent or hexavalent form. The trivalent form of $\mathrm{Cr}$ is considered to be relatively harmless, whereas various mechanisms of toxicity, carcinogenicity and allergenicity of the hexavalent form have been reported (Dayan and Paine, 2001).
Due to their excellent material properties, Cr-based implants are widely used in clinical practice. In clinical trials, implantation of Cr-based screws or rods (stainless-steel, CoCr) showed postoperative outcomes similar to those for $\mathrm{Ti}$ implants (Angelliaume et al., 2017; Chang et al., 2019). In some orthopaedic applications, CoCr implants (rods) were even more suitable than Ti implants (Angelliaume et al., 2017).

Doping the DLC layer with $\mathrm{Cr}$ improves the adhesion of this layer to the substrate surface (Dai et al., 2010; Jelinek et al., 2016a), and this improvement is more pronounced than in Ti-doped DLC films. In an earlier study it was shown that, under a critical mechanical load, the delaminated pieces of the layers were larger in Ti-doped DLC than in Cr-doped DLC. In addition, $\mathrm{Cr}$-doped DLC films were harder than Ti-doped DLC films (Jelinek et al., 2017). Modifying DLC with $\mathrm{Cr}$ could therefore be advantageous for coating biomedical implants; however, the biological effect of the $\mathrm{Cr}$ added in the DLC layer needs to be elucidated.

The aim of this study was to analyse the possible effect of Cr-doped DLC layers, of different $\mathrm{Cr}$ concentrations, on cell adhesion and cell metabolic activity - using human bone marrow mesenchymal stromal cells (hMSCs) and neonatal human dermal fibroblasts (NHDF) - on osteogenic cell differentiation (using hMSCs), on cell immune activation (using mouse RAW 264.7 macrophage-like cells) and on apoptosis (using NHDF and human osteoblast-like Saos- 2 cells). The results of the current study indicated that Cr-doped DLC layers with optimised Cr content have suitable chemical, physical and biological properties. When used as coatings for metallic prostheses, Cr-doped DLC layers could improve the osseointegration, the long-term biocompatibility and the functionality of metallic prostheses for use in humans.

\section{Materials and Methods}

\section{Preparation and characterisation of Cr-doped DLC layers}

DLC layers doped with Cr were prepared by a hybrid laser technology combining simultaneous pulsedlaser deposition (PLD) and magnetron sputtering on fused silica substrates, at room temperature. A precise description of this process has already been published (Jelinek et al., 2015; Jelinek et al., 2017; Jelinek et al., 2016b). Briefly, for the deposition, a KrF excimer laser was used for carbon deposition, while a magnetron (2-inch, K. J. Lesker) sputtered chromium species $(\sim 5 \mathrm{eV})$. The substrates (glass wafers) were cleaned ultrasonically in acetone, toluene and ethanol and were dried in air before being placed in the vacuum chamber. The substrates were also cleaned by radiofrequency discharge before deposition for $2 \mathrm{~min}$ at a power of $100 \mathrm{~W}$ in a $5 \mathrm{~Pa}$ Ar atmosphere. 
To fabricate DLC with a variable $\mathrm{Cr}$ content, the repetition rate of the laser ranged between 3 and $40 \mathrm{~Hz}$. The energy density of the laser radiation was held at $8 \mathrm{Jcm}^{-2}$, and the magnetron power was 40 or $80 \mathrm{~W}$ (Table 1). The substrate (glass wafer) was at a distance of $45 \mathrm{~mm}$ from the laser target and $125 \mathrm{~mm}$ from the magnetron target (purity, graphite: $99.999 \%$; Cr: $99.95 \%$ ) (Kurt J. Lesker Company, Hastings, UK).The films were deposited in Ar ambient (0.4$0.5 \mathrm{~Pa}$ ) at room temperature. The samples' $\mathrm{Cr}$ content, expressed as atomic percent (at.\%), were characterised using X-ray photoelectron spectroscopy (XPS) and Wavelength-dispersive $\mathrm{X}$-ray spectroscopy (WDX), as well as for their wettability and surface free energy. The XPS method was performed using 2 different spectrometers; namely by an ADES 400 (XPS1) angle-resolved photoelectron spectrometer (VG Scientific, East Grinstead, UK), and by an ultrahigh vacuum AXIS-Supra photoelectron spectrometer (XPS2) (Kratos Analytical Ltd., Manchester, UK) (Table 1). WDX was performed using a JEOL 840 instrument (JEOL Ltd., Tokyo, Japan). The following samples were prepared and evaluated in the present study: sample No. 82 (pure DLC; 0 at.\% Cr), No. 84 (0.9 at.\% Cr), No. 86 (1.8 at.\% Cr), No. 88 (7.3 at.\% Cr), and No. 90 (7.7 at.\% Cr).

\section{Cell models and studied samples}

In the experiments, the following cell models were used: mouse macrophage-like RAW 264.7 cells (Cat. No. 91062702, ECACC, Salisbury, UK), hMSCs (cells originated from a single donor, Cat. No. 7500, ScienCell Research Laboratories, CA, USA), human osteoblast-like Saos-2 cells (ECACC, UK), and NHDF (cells originated from a single donor, Lonza Walkersville Inc., MD, USA).

Samples of a pure DLC layer (sample 82) and DLC layers with a $\mathrm{Cr}$ content of $0.9,1.8,7.3$ and 7.7 at.\% (samples 84, 86, 88 and 90, respectively), were sterilised in $70 \%$ ethanol for $2 \mathrm{~h}$ before cell seeding. Pure DLC and standard cell culture materials, namely tissue culture polystyrene (PS) and microscopy glass coverslips (Gl), were used as reference samples. A pure DLC sample is the most suitable control for an evaluation of the effect of $\mathrm{Cr}$ doping. Standard cell culture materials were used to provide a broader context for a comparison of cell behaviour on different material surfaces. Tissue culture PS was used because it is a widely-used cell culture substrate, reflecting standard cell behaviour under in vitro conditions. The glass coverslips had physicochemical characteristics similar to those of the silica substrates used for the deposition of DLC layers.

Energy dispersive spectrometry (EDS) and atomic absorption spectrophotometry (AAS) analyses of cultivation media $\mathrm{Cr}$ content

Culture conditions

For measurements of the $\mathrm{Cr}$ content in the cell culture medium, RAW 264.7 cells were used. The RAW 264.7
Table 1. Deposition parameters and chromium content of the DLC and Cr-doped DLC samples.

\begin{tabular}{|c|c|c|c|c|c|}
\hline \multirow{2}{*}{$\begin{array}{l}\text { Sample } \\
\text { No. }\end{array}$} & \multirow{2}{*}{$\begin{array}{c}\text { Laser rate } \\
{[\mathrm{Hz}]}\end{array}$} & \multirow{2}{*}{$\begin{array}{l}\text { Magnetron } \\
\text { [W] }\end{array}$} & \multicolumn{3}{|c|}{$\begin{array}{c}\text { Chromium content } \\
\text { [at. \%] }\end{array}$} \\
\hline & & & XPS1 & XPS2 & WDX \\
\hline 82 & 20 & 0 & 0.0 & 0.0 & - \\
\hline 84 & 40 & 40 & 0.9 & 0.9 & 1 \\
\hline 86 & 20 & 40 & 1.5 & 1.8 & 2 \\
\hline 88 & 10 & 40 & 3.7 & 7.3 & $4-5$ \\
\hline 90 & 3 & 40 & 7.1 & 7.7 & $15-17$ \\
\hline
\end{tabular}

cells were seeded at a density of 30,000 cells/well in $1.5 \mathrm{~mL}$ of RPMI-1640 medium (Cat. No. R8758, Sigma-Aldrich, St. Louis, MO, USA) with $10 \%$ of foetal bovine serum (FBS; Cat. No. F7524-500ML, Sigma-Aldrich) on DLC samples, and on glass in 24well PS tissue-culture test plates (TPP, Trasadingen, Schaffhausen, Switzerland). On days 3 and 7, the culture medium was taken from both DLC- and PS-based samples, centrifuged at $600 \times g$ for $5 \mathrm{~min}$ in order to remove non-adherent cells, and stored at $-80^{\circ} \mathrm{C}$. Subsequently, the stored medium was used for an analysis of the $\mathrm{Cr}$ content.

\section{EDS and AAS analyses}

The release of $\mathrm{Cr}$ into the cell culture medium was measured using EDS and AAS analyses. The investigation of the $\mathrm{Cr}$ content in the cell culture medium of RAW 264.7 cells, after $3 \mathrm{~d}$ and $7 \mathrm{~d}$ culture intervals, was carried out using a Quanta 450 scanning electron microscope (FEI, Thermo Fisher Scientific, Hillsboro, OR, USA), equipped with an Apollo XL Silicon Drift Detector 1 EA EDS attachment (EDAX Inc., Mahwah, NJ, USA), at a nominal magnification of $1,000 \times$ and accelerating voltage $12.5 \mathrm{kV}$. Prior to the EDS analyses, $10 \mathrm{~mL}$ of the medium from each triplicate was frozen at $-17^{\circ} \mathrm{C}$ overnight and then lyophilised at $-105^{\circ} \mathrm{C}$ at a pressure of approx. 1.3 Pa (BenchTop 4KZL, VirTis, Warminster, PA, USA). Particles of the dried medium were attached by carbon tape to an aluminium stub, and were carbon coated under vacuum in a K550X device (EMITech - Quorum, Laughton, East Sussex, UK). The weight and the atomic fractions of the chemical elements incorporated in the dried medium were characterised. 5 areas $\left(250 \times 250 \mu \mathrm{m}^{2}\right)$ were analysed for each triplicate. The $\mathrm{Cr}$ concentration in the medium, following cell cultivation, was measured in triplicate using an AAS by the $\mathrm{N}_{2} \mathrm{O}$ /acetylene flame atomisation technique at $357.9 \mathrm{~nm}$, using a Varian SpectrAA 880 apparatus (Varian, Mulgrave, Victoria, Australia).

\section{The adhesion, growth and osteogenic differentiation of hMSCs}

Culture conditions

Before the experiments, the hMSCs were cultured in Mesenchymal Stem Cell Medium (MSCM; Cat. No. 7501, ScienCell Research Laboratories, Carlsbad, CA, 
USA) in $75 \mathrm{~cm}^{2}$ PS tissue culture flasks (TPP) coated with poly-L-lysine (0.01 \%, P4707, Sigma-Aldrich).

The hMSCs were seeded on the samples at a density of 9,000 viable cells/1.5 mL/well (i.e. 5,000 cells $/ \mathrm{cm}^{2}$ ) in 24-well tissue-culture test plates in $\alpha$-MEM medium (Cat. No. 11900-016, Gibco, Waltham, MA, USA) supplemented with FBS (15\%), L-glutamine (2 mmol/L; Cat. No. A2916801, Gibco) and gentamicin $(40 \mu \mathrm{g} / \mathrm{mL}$; LEK, Ljubljana, Slovenia). The hMSCs were cultured at $37{ }^{\circ} \mathrm{C}$ in a humidified air atmosphere with $5 \% \mathrm{CO}_{2}$ for $21 \mathrm{~d}$. From day 3 , this medium was enriched with dexamethasone (10 nmol/L; Cat. No. D2915, Sigma-Aldrich), $\beta$-glycerophosphate $(20 \mathrm{mmol} / \mathrm{L}$; Cat. No. G9422, Sigma-Aldrich) and ascorbic acid (50 $\mu \mathrm{mol} / \mathrm{L}$; Cat. No. 49752-10G, Sigma-Aldrich) in order to support potential osteogenic differentiation of the cells. This medium was replaced twice per week.

\section{Metabolic activity of cells}

The cell metabolic activity is an indirect marker of the number and proliferation of cells. The metabolic activity of the hMSCs on days 1, 3, 7, 14 and 21 after seeding was measured by resazurin (Cat. No. R7017, Sigma-Aldrich) conversion; $n=3$ for each experimental group. $4 \mathrm{~h}$ incubation was used on days 1 and 3 , and $2.5 \mathrm{~h}$ incubation was used on days 7,14 and 21. Briefly, the stock solution of resazurin ( $4 \mathrm{mmol} / \mathrm{L}$ ) was added to the cultivation medium without phenol red to a final concentration of $40 \mu \mathrm{mol} / \mathrm{L}$. Then, $1 \mathrm{~mL}$ of this medium was added to cells pre-washed with phosphate-buffered saline (PBS; Sigma-Aldrich) in order to remove the original medium. After incubation with the medium with resazurin at $37{ }^{\circ} \mathrm{C}$, the fluorescence was measured $(\mathrm{Ex} / \mathrm{Em}=530 / 590 \mathrm{~nm})$ and was corrected to the background control (solvent mixture without cells) on a Synergy ${ }^{\mathrm{TM}}$ HT Multi-Mode Microplate reader (BioTek, Winooski, VT, USA). The cell metabolic activity was used as an indirect indicator of cell proliferation.

Immunofluorescence staining of cell adhesion and osteogenic differentiation markers, and measurements of cell-spreading area

Immunofluorescence staining was used for visualising and quantifying vinculin, a marker of cell adhesion (day 1), and markers of osteogenic cell differentiation, i.e. type I collagen and osteocalcin (days 7, 14). On days 1, 7 and 14, the samples with hMSCs were washed in PBS and fixed with $4 \%$ paraformaldehyde for $10 \mathrm{~min}$ (pH 7.4). Subsequently, they were washed twice in PBS for $5 \mathrm{~min}$, pre-treated with $1 \%$ bovine serum albumin in PBS containing $0.1 \%$ Triton X-100 for $20 \mathrm{~min}$, and were then incubated in $1 \%$ Tween 20 for $20 \mathrm{~min}$. After being rinsed twice for $5 \mathrm{~min}$ in PBS, the primary antibodies, i.e. monoclonal anti-vinculin, mouse ascites fluid, clone hVIN-1 (V 9131, dilution 1 : 200 in PBS; Sigma-Aldrich), or polyclonal rabbit anti-osteocalcin (1-49) (human) IgG (T-4743, dilution 1 : 200 in PBS; Peninsula Laboratories Inc, San Carlos,
CA, USA), were applied overnight at $4{ }^{\circ} \mathrm{C}$. Mouse monoclonal anti-type I collagen, mouse ascites fluid, clone col-1 (C2456, dilution 1 : 200; Sigma-Aldrich), was applied for $3 \mathrm{~h}$ at room temperature. After being washed in PBS, the secondary antibodies, i.e. F(ab') fragment of goat anti-mouse IgG $(\mathrm{H}+\mathrm{L})$, conjugated with Alexa Fluor 488 or Alexa Fluor 546 (A11017 or A11003, dilution 1 : 400; Thermo Fisher Scientific, Waltham, MA, USA) or Alexa Fluor 488-conjugated $\mathrm{F}\left(\mathrm{ab}^{\prime}\right)$ fragment of goat anti-rabbit IgG $(\mathrm{H}+\mathrm{L})$ (A11070, dilution 1 : 400; Thermo Fisher Scientific) were used for $60 \mathrm{~min}$ at room temperature. F-actin (day 1) was stained using phalloidin conjugated with tetramethylrhodamine (TRITC) $(5 \mu \mathrm{g} / \mathrm{mL}$ in PBS, Cat. No. P1951, Sigma-Aldrich) for $1 \mathrm{~h}$ at room temperature. The cell nuclei were counterstained with Hoechst \#33258 (B1155, $10 \mu \mathrm{g} / \mathrm{mL}$ in PBS, Sigma-Aldrich) for $60 \mathrm{~min}$ on days 1, 7 and 14 . Photomicrographs of randomly chosen microscopic fields, evenly distributed on the material substrate, were captured using an epifluorescence IX71 microscope equipped with a DP71 digital camera (both from Olympus, Tokyo, Japan). On day 1, the cell spreading area of 84 to 122 cells stained for vinculin on each sample was analysed on photomicrographs, using TESCAN Atlas software (TESCAN s.r.o., Brno, Czech Republic). On days 7 and 14, in order to measure the fluorescence intensity of type I collagen and osteocalcin, 5-6 micrographs of randomly selected fields on each sample were taken using the epifluorescence microscope at the same exposure time; $3 \mathrm{~s}$ for type I collagen and $1 \mathrm{~s}$ for osteocalcin. The fluorescence intensity was then normalised per cell. The fluorescence intensity of the samples stained only with secondary antibody, i.e. without primary antibodies, was subtracted.

\section{Alkaline phosphatase (ALP) activity}

On days 7, 14 and 21 after seeding, the ALP activity of the hMSCs was measured ( $n=3$ for each experimental group). The cells were washed twice in PBS and then the substrate solution, i.e. $0.1 \mathrm{mg} / \mathrm{mL}$ p-nitrophenyl phosphate in the substrate buffer $(50 \mathrm{mmol} / \mathrm{L}$ glycine, $1 \mathrm{mmol} / \mathrm{L} \mathrm{MgCl}_{2}, \mathrm{pH}$ 10.5) (Sigma-Aldrich), was added. The cells were incubated in the substrate solution for $7.5 \mathrm{~min}$ at room temperature, and then $600 \mu \mathrm{L}$ of the solution was added into an equal amount of $1 \mathrm{~mol} / \mathrm{L} \mathrm{NaOH}$. A calibration curve was prepared using 9-90 $\mu \mathrm{mol} / \mathrm{L}$ p-nitrophenol (Sigma-Aldrich). The absorbance of the samples was measured at $405 \mathrm{~nm}$. The results were then normalised to the cell metabolic activity measured by the resazurin assay.

\section{Calcium deposition}

On days 14 and 21 following seeding, the hMSCs cells on the DLC samples $(n=2$ for each experimental group) were washed twice in PBS, were dried for $3 \mathrm{~h}$, and were then incubated on a shaker in $0.5 \mathrm{~mol} / \mathrm{L}$ $\mathrm{HCl}$ at $4{ }^{\circ} \mathrm{C}$ overnight. Supernatants obtained after centrifugation of the cell lysates were analysed using a Calcium Colorimetric Assay (Cat. No. MAK022-1KT, 
Sigma-Aldrich) according to the standard manufacturer's protocol. The results were then normalised to the cell metabolic activity on the same day.

Real-time qPCR of markers of cell osteogenic differentiation For an evaluation of the osteogenic differentiation of hMSCs, real-time quantitative PCR (qPCR) was used to reveal the changes in the expression of genes for Runt-related transcription factor 2 (RUNX2), type I collagen, alkaline phosphatase $(A L P)$, and osteocalcin on days 3, 5, 7, 10, 14 and 21 after seeding (Table 2); $n=3$ for each experimental group. Cells were grown on the Cr-doped DLC substrates for $3 \mathrm{~d}$; then, the proliferation medium ( $\alpha$-MEM medium with $15 \%$ of FBS) was exchanged for the differentiation medium (the same medium supplemented with osteogenic factors; see above).

Total RNA was extracted from the cells using a Total RNA purification Micro Kit (NORGENE Biotek Corp, Cat. No. 35300, Thorold, Canada), according to the manufacturer's instructions. The mRNA concentration was measured using NanoPhotometer ${ }^{\mathrm{TM}} \mathrm{S} / \mathrm{N}$ (IMPLEN, Munich, Germany). The cDNA was synthesised with the ProtoScript ${ }^{\circledR}$ M-MuLV First Strand cDNA Synthesis kit (New England BioLabs, Cat. No. E6300S, Ipswich, MA, USA), using $250 \mathrm{ng}$ of total RNA and oligo(dT) primers. The reaction was performed in a T-Personal Thermocycler (Biometra, Göttingen, Germany). The qPCR primers were purchased from Generi Biotech Ltd. (Hradec Kralove, Czech Republic). and are listed in Table 2. The primers were designed according to the literature (Frank et al., 2002; Leiber et al., 2014; Neophytou et al., 2014; Reseland et al., 2006; Zhang et al., 2010). Real-time qPCR was performed using SYBR Green (Roche, Basel, Switzerland) in the total reaction volume of $20 \mu \mathrm{L}$ and the iCycler detection system (iQ ${ }^{\mathrm{TM}} 5$ Multicolor Real-Time PCR Detection
System, Bio-Rad, Hercules, California, USA) with cycling parameters of $10 \mathrm{~min}$ at $95^{\circ} \mathrm{C}$, then 40 cycles of $15 \mathrm{~s}$ at $95{ }^{\circ} \mathrm{C}$ and $1 \mathrm{~min}$ at $60{ }^{\circ} \mathrm{C}$, followed by a melt curve. The assays were conducted in quadruplicate. Data were analysed by the $2^{-\Delta \Delta C t}$ method. The point at which the PCR product was first detected above a fixed threshold (referred to as cycle threshold, $\mathrm{C}_{\mathrm{t}}$ ), was determined for each sample. Changes in the expression of target genes were calculated using the equation:

$$
\Delta \Delta C_{t}=\left(C_{t}^{\text {target }}-C_{t}^{G A P D H}\right)_{\text {sample }}-\left(C_{t}^{\text {target }}-C_{t}^{G A P D H}\right)_{\text {calibrator }}
$$

Glyceraldehyde 3-phosphate dehydrogenase $(G A P D H)$ was used as a housekeeping gene. The data for evaluating the cell differentiation were normalised to the level of gene expression of the hMSCs grown on the tissue culture PS on day 3 after seeding before adding the osteogenic medium.

\section{Cell immune activation and cytokine production}

For an evaluation of the cell immune response as estimated by cytokine production, cultures of RAW 264.7 cells were used. This cell line has phagocytic activity, produces reactive oxygen species (ROS) and nitric oxide synthase, and is able to produce inflammatory cytokines upon stimulation (Asgharpour et al., 2019; McCall et al., 2010; van Berlo et al., 2014).

\section{Culture conditions}

The RAW 264.7 cells were seeded at a density of 30,000 cells/well in $1.5 \mathrm{~mL}$ of RPMI-1640 medium (Sigma-Aldrich) with $10 \%$ of FBS on DLC samples, and on glass in 24-well PS tissue-culture test plates (TPP).

As a positive control for the cell immune response, RAW 264.7 cells were cultured on PS in RPMI1640 medium with $10 \%$ of FBS for $3 \mathrm{~d}$, into which

Table 2. Oligonucleotide primers. Oligonucleotide primers for real-time Q-PCR amplification.

\begin{tabular}{|c|c|c|}
\hline Gene & Primer sequence & Product size (bp) \\
\hline RUNX2 & $\begin{array}{c}\text { Forward: 5'-GCCTTCAAGGTGGTAGCCC-3' } \\
\text { Reverse: 5'-CGTTACCCGCCATGACAGTA-3' }\end{array}$ & 100 \\
\hline Type I collagen & $\begin{array}{c}\text { Forward: 5'-CAGCCGCTTCACCTACAGC -3' } \\
\text { Reverse: 5'-TTTTGTATTCAATCACTGTCTTGCC-3' }\end{array}$ & 83 \\
\hline ALP & $\begin{array}{c}\text { Forward: 5'-GACCCTTGACCCCCACAAT-3' } \\
\text { Reverse: 5'-GCTCGTACTGCATGTCCCCT-3' }\end{array}$ & 68 \\
\hline Osteocalcin & $\begin{array}{c}\text { Forward: 5'-GAAGCCCAGCGGTGCA-3' } \\
\text { Reverse: 5'-CACTACCTCGCTGCCCTCC-3' }\end{array}$ & 70 \\
\hline Bax & $\begin{array}{c}\text { Forward: 5'-GACGTGGGCATTTTTCTTAC-3' } \\
\text { Reverse: 5'-GTGTCCCGAAGGAGGTTTAT-3' }\end{array}$ & 87 \\
\hline Bid & $\begin{array}{c}\text { Forward: 5'-TGGTGTTTGGCTTCCTCCAA-3' } \\
\text { Reverse: 5'-GAATCTGCCTCTATTCTTCCC-3' }\end{array}$ & 169 \\
\hline Bim & $\begin{array}{c}\text { Forward: 5'-GAGCCACAAGACAGGAGC-3' } \\
\text { Reverse: 5'-CCATTGCACTGAGATAGTGG-3' }\end{array}$ & 100 \\
\hline BCL-XL & $\begin{array}{c}\text { Forward: 5'-GTAAACTGGGGTCGCATTGT-3' } \\
\text { Reverse: 5'-TGGATCCAAGGCTCTAGGTG-3' }\end{array}$ & \\
\hline GAPDH & $\begin{array}{c}\text { Forward: 5'-TGCACCACCAACTGCTTAGC-3' } \\
\text { Reverse: 5'-GGCATGGACTGTGGTCATGAG-3' }\end{array}$ & 87 \\
\hline
\end{tabular}


lipopolysaccharides from Escherichia coli 026:B6 (LPS, Sigma-Aldrich) at a concentration of 1, 10, 100 and $1000 \mathrm{ng} / \mathrm{mL}$ were added $24 \mathrm{~h}$ after seeding. Images of living cells were taken on days 3 and 7 , and the cells were counted from 23-30 micrographs for each sample. On days 3 and 7 , the culture medium was taken from each sample (all in three parallels), was centrifuged at $600 \times g$ for $5 \mathrm{~min}$ in order to remove non-adherent cells, and was stored at $-80^{\circ} \mathrm{C}$. These medium samples were analysed for the presence of 40 cytokines. On day 3, a quantitative analysis of cellspreading area of cells cultured on PS with LPS and of cells cultured on DLC-based samples without LPS was performed using ImageJ FIJI software (Schindelin et al., 2012). From 200 to 400 cells were analysed for each sample based on native microscopy images.

\section{RayBio ${ }^{\mathrm{TM}}$ Human Cytokine Array}

The Human Inflammation Array C3 (8), 8 Sample Kit (AAH-INF-3-8, Raybiotech, Peachtree Corners, GA, USA) was used for screening 40 cytokines. The array was processed according to the manufacturer's protocol ( $n=2$ for each experimental group). Briefly, the solid nitrocellulose membranes printed with specific antibodies were blocked by incubation with the blocking buffer, and were incubated with the medium taken from the tested samples with RAW 267.4 cells. The membranes were incubated with a biotin-conjugated antibody cocktail. Then, the membranes were incubated with horseradishperoxidase-conjugated streptavidin. Next, the membranes were incubated with the detection buffer. The membranes were washed with wash buffers after each step of the procedure. The cytokines bound to the membranes were detected in a luminescence detector (LAS-1000, Fujifilm, Tokyo, Japan). The data were analysed using AIDA 3.28 image analysis software (Raytest $\mathrm{GmbH}$, Straubenhardt, Germany). The measured values were correlated with a positive control, which was taken as a value of 1.00 . The positive control contained a controlled amount of biotinylated antibody printed onto the membrane. The following cytokines were analysed: eotaxin-1, eotaxin-2, granulocyte colony stimulating factor (G-CSF), macrophage colony stimulating factor (M-CSF), granulocyte-macrophage colony stimulating factor (GM-CSF), chemokine (C-C motif) ligand 1 (CCL-1, I-309), intercellular adhesion molecule-1 (ICAM-1), interferon- $\gamma($ IFN- $\gamma$ ), various interleukins (IL), namely IL-10, IL-11, IL-12p40, IL12p70, IL-13, IL-15, IL-16, IL-17, IL-1 $\alpha$, IL-1 $\beta$, IL-2, IL3, IL-4, IL-6, IL-6sR, IL-7, IL-8, interferon $\gamma$-induced protein 10 (IP-10)/CXCL10, monocyte chemotactic proteins 1 and 2 (MCP-1 and MCP-2, respectively), monokine induced by interferon-gamma (MIG/ CXCL9), macrophage inflammatory proteins (MIP), namely MIP-1 $\alpha$, MIP-1 $\beta$, MIP-1 $\delta$, plateletderived growth factor-BB (PDGF-BB), Regulated on Activation, Normal T cell Expressed and Secreted (RANTES) protein, transforming growth factor- $\beta 1$ (TGF- $\beta 1)$, tissue inhibitor of metalloproteinase-2
(TIMP-2), tumour necrosis factors $\alpha$ and $\beta$ (TNF- $\alpha$, TNF- $\beta$, respectively), and soluble TNF receptors (sTNFR) I and II. The values obtained from all membranes were normalised per 100,000 cells.

\section{Apoptosis analysis}

The apoptosis analysis was performed on Saos-2 cells. The Saos- 2 cell line is widely used as an in vitro model for studying the differentiation of osteoblasts to osteocytes; however, Saos-2 cells are p53-deficient, which can influence their response to an apoptotic stimulus. Therefore, NHDFs was also used as a representative of primary mature mesenchymal cells. In addition, these cells were used for an evaluation of the cell number on the tested samples.

\section{Culture conditions}

The Saos- 2 cells were seeded on samples at a density of 37,000 cells/well $\left(20,000\right.$ cells/ $\left.\mathrm{cm}^{2}\right)$ in $1 \mathrm{~mL}$ of McCoy's 5A medium (M4892, Sigma-Aldrich) with $15 \%$ of FBS in 24-well culture plates. On day 9, apoptosis was evaluated by the expression of selected anti- and pro-apoptotic genes using qPCR.

NHDFs were seeded on the tested samples at a density of 30,000 cells/well $\left(16,000\right.$ cells $\left./ \mathrm{cm}^{2}\right)$ in $1 \mathrm{~mL}$ of DMEM medium with $10 \%$ of FBS in 24well culture plates. On days 1 and 3, the cells were fixed with frozen $70 \%$ ethanol, and were stained with Hoechst \#33258 to visualise the cell nuclei. Images of the cells were taken, and the cells were counted from 48 micrographs on each sample. On day 7 , the cell number was estimated using resazurin conversion after a $4 \mathrm{~h}$ incubation. The cell number was recalculated to the substrate area. On day 9, apoptosis was evaluated by the expression of selected anti- and pro-apoptotic genes using qPCR.

For flow cytometry analysis of annexin $\mathrm{V}$-positive cells on Cr-doped DLC, both Saos-2 and NHDF cells were evaluated on day 2 of cultivation.

\section{Real-time qPCR of markers of apoptosis}

For an evaluation of apoptosis in NHDF and Saos2 cells, the real-time qPCR was used to determine the level of expression of an anti-apoptotic gene encoding B-cell lymphoma-extra large (BCL-XL) transmembrane protein in mitochondria, and also the level of expression of pro-apoptotic genes encoding Bcl-2-associated X protein (Bax), Bcl-2-like protein 11 (Bim), BH3 interacting-domain death agonist (Bid). Cells were grown on the Cr-doped DLC substrates for $9 \mathrm{~d}$. Cells treated with camptothecin $(4 \mu \mathrm{g} / \mathrm{mL}$; Cat. No. sc-200871, Santa Cruz Biotechnology, Dallas, TX, USA), i.e. a natural alkaloid inducing apoptosis, served as a positive control. Camptothecin was added to the medium of half of the samples $2 \mathrm{~d}$ before the end of the experiment (i.e. on day 7 after seeding); $n=2$ for each experimental group. The procedure for RNA extraction, cDNA synthesis and real-time qPCR was identical to that described in the section Real-time qPCR of markers of cell osteogenic differentiation, above, with the primers listed in Table 2. 
The data for evaluating cell apoptosis was normalised to the expression levels of the cells grown on PS (calibrator).

Quantification of apoptotic cells using the annexin $V$ assay for flow cytometry

Flow cytometry was used to quantify the annexin V-positive apoptotic cells. A single cell suspension was prepared from the adherent cells, together with cells from the cell culture medium, using standard trypsin-EDTA solution (SigmaAldrich). The cells were washed with PBS containing $10 \%$ of FBS. Then, the cells were incubated at $4^{\circ} \mathrm{C}$ in a binding buffer $(100 \mu \mathrm{L} ; 10 \times$ annexin V Binding Buffer, Cat. No. 556454, BD Biosciences, San Jose, CA, USA) containing $2 \mu \mathrm{L}$ of annexin-V-FLUOS and $2 \mu \mathrm{L}$ of propidium iodide (annexin-V-FLUOS Staining Kit, Cat. No. 11988549001, Roche) in the dark for $15 \mathrm{~min}$. Afterwards, $400 \mu \mathrm{L}$ of binding buffer was added and the fluorescence of the annexin-V-FLUOS and propidium iodide (PI) was detected using an Accuri C6 Flow Cytometer (BD Biosciences), and the data (from 20,000 cells for each experimental group) were analysed with CFlow ${ }^{\circledR}$ Plus software (BD Biosciences). Cells positive for annexin-V-FLUOS were considered to be apoptotic, whereas cells positive for both PI and annexin-V-FLUOS were considered to be necrotic.

\section{Statistical evaluation}

The quantitative data are presented as mean \pm SEM (Standard Error of Mean) for biological experiments, with the exception of PCR. The PCR data are presented as mean \pm SD (Standard Deviation) from 3 measurements. Statistical analyses were performed using SigmaStat (Systat Software Inc., San Jose, CA, USA). Multiple comparison procedures were performed by One Way Analysis of Variance (ANOVA), Student-Newman-Keuls methods. Probability of $p \leq 0.05$ was considered significant. In the PCR measurements, a probability of $p \leq 0.01$ (Figs. 3, 4) or $p \leq 0.05$ (Figs. 10,11) was considered significant.

\section{Results}

\section{Characterisation of $\mathrm{Cr}$-doped layers}

Table 1 summarises previously-published deposition parameters and $\mathrm{Cr}$-content measurements (Jelinek et al., 2015; Jelinek et al., 2017; Jelinek et al., 2016b). The Cr content in the prepared samples was analysed using 2 separate spectrometers, resulting in slightly different values. The distinction between the measured $\mathrm{Cr}$ content values may be due to the different methods that were used. XPS mainly provided an analysis of the upper surface area, i.e. of a measured area of approx. $0.2 \mathrm{~mm}^{2}$ that was $\sim 5 \mathrm{~nm}$ in thickness. By contrast, the WDX method analysed a deeper part of the material, i.e. a measured area of $\sim 0.002 \mathrm{~mm}^{2}$ that was $\sim 500 \mathrm{~nm}$ in thickness. The composition of the superficial layer of Cr-doped DLC is important for cell-material interactions, so the XPS2 data were used for labelling the samples.

\section{EDS and AAS analyses of $\mathrm{Cr}$ content in the cultivation media}

The presence of $\mathrm{Cr}$ in lyophilised cultivation media after RAW 264.7 cell cultivation was assessed (data not shown). In the EDS spectra, $\mathrm{Cr}$ peaks were expected at $K_{\alpha}$ energy of 5.414 and at $K_{\beta}$ energy of 5.946. EDS did not prove the presence of $\mathrm{C} r$ in any of the investigated medium samples. Similarly, no $\mathrm{Cr}$ was detected by the AAS method (with a detection limit of $0.1 \mathrm{ppm})$.

\section{Cell adhesion, morphology, spreading, growth dynamics and metabolic activity of hMSCs}

On day 1 after seeding, the hMSCs had a polygonal shape and were well spread on all samples (Fig. 1). The cell-spreading area values varied from 2,839 $\pm 184 \mu^{2}$ (PS) to $3,565 \pm 217 \mu \mathrm{m}^{2}$ (sample 82 ), but there was no statistically significant difference between the samples. Immunofluorescence staining for vinculin (Fig. 1) generally showed a diffuse signal; however, a more apparent assembly of vinculin-containing focal adhesion plaques was observed in cells on samples with a higher $\mathrm{Cr}$ content, especially at the cell borders. The cells on all samples were positively stained for F-actin, and these actin stress fibres were mostly oriented in the same direction (Fig. 1). The morphology of the cells on day 3 was polygonal, and the cells were homogeneously distributed on all tested samples (data not shown).

The proliferation of the hMSCs was estimated by resazurin conversion. During $21 \mathrm{~d}$ of culture, the cell metabolic activity of hMSCs increased gradually. On day 1 after seeding, the metabolic activity of hMSCs was similar on all samples except for the DLC layer doped with 0.9 at.\% of $\mathrm{Cr}$ (sample 84, Fig. 2a), where the value was significantly lower than the value on PS. On day 3, significantly lower metabolic activity was found on the DLC layer doped with 7.7 at.\% of $\mathrm{Cr}$ (sample 90, Fig. 2a) than on PS. On day 7, the metabolic activity of hMSC was similar on all samples (Fig. 2b). On day 14, higher values of metabolic activity were obtained on the DLC-based samples 82 (pure DLC), 86 (1.8 at.\% of Cr), 88 (7.3 at.\% of Cr), and 90 (7.7 at.\% of $\mathrm{Cr}$ ) than on the control PS sample (Fig. 2b). On the day 21 of cell culture, the hMSCs had similar metabolic activity on all samples.

\section{Osteogenic differentiation on the RNA level (qPCR)}

4 different markers involved in osteogenic differentiation, namely RUNX2 (Fig. 3a), type I collagen (Fig. 3b), ALP (Fig. 4a), and osteocalcin (Fig. 4 b), were evaluated using qPCR in intervals of 5,7 , 10,14 and $21 \mathrm{~d}$ of hMSCs culture. A control interval of $3 \mathrm{~d}$ on PS in the standard culture medium without osteogenic factors was used as a calibrator to observe the dynamics in the expression of selected genes. In general, RUNX2, type I collagen and ALP showed 

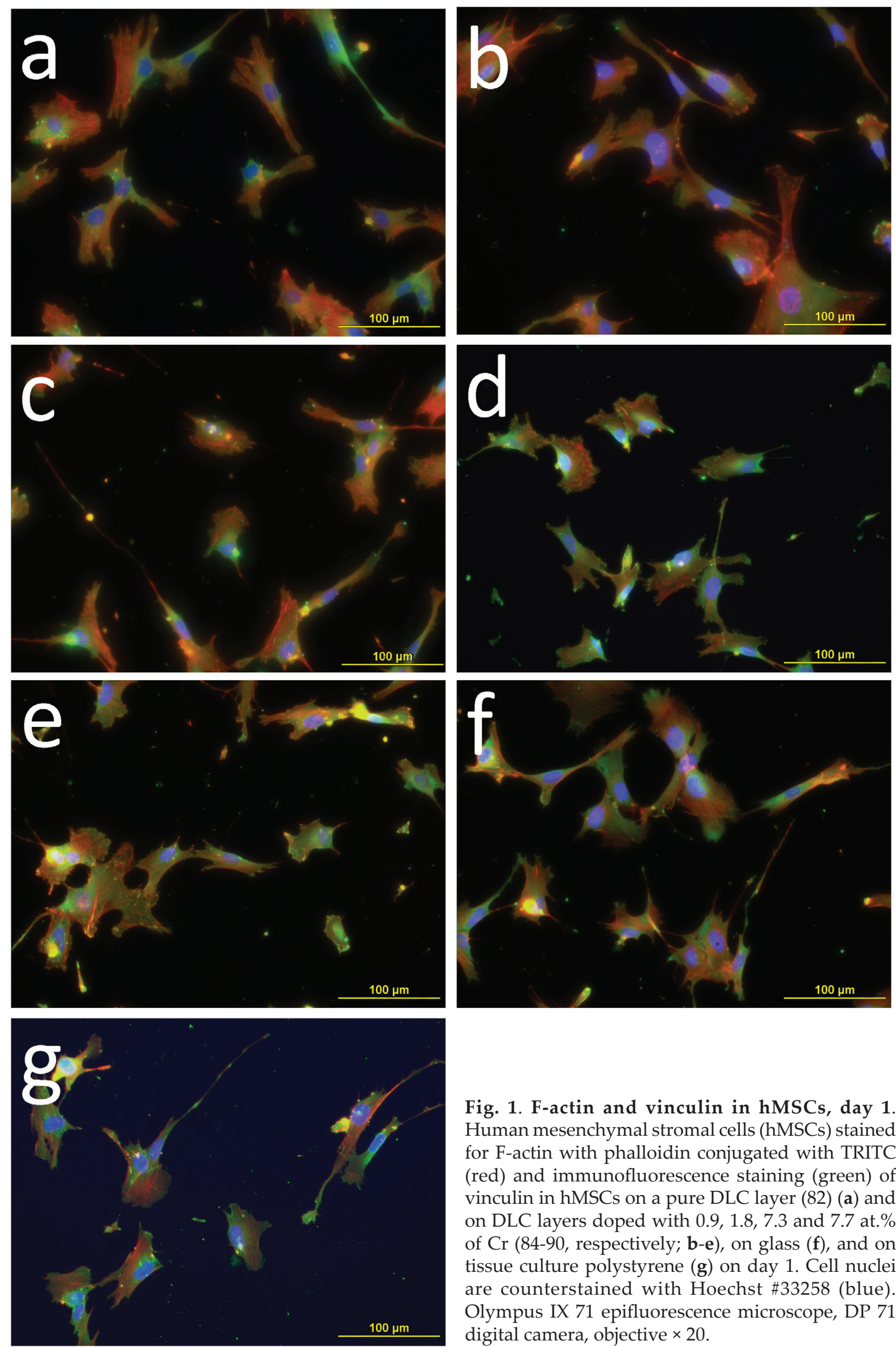

Fig. 1. F-actin and vinculin in hMSCs, day 1 . Human mesenchymal stromal cells (hMSCs) stained for F-actin with phalloidin conjugated with TRITC (red) and immunofluorescence staining (green) of vinculin in hMSCs on a pure DLC layer (82) (a) and on DLC layers doped with $0.9,1.8,7.3$ and 7.7 at.\% of Cr (84-90, respectively; b-e), on glass (f), and on tissue culture polystyrene $(\mathrm{g})$ on day 1 . Cell nuclei are counterstained with Hoechst \#33258 (blue). Olympus IX 71 epifluorescence microscope, DP 71 digital camera, objective $\times 20$. 

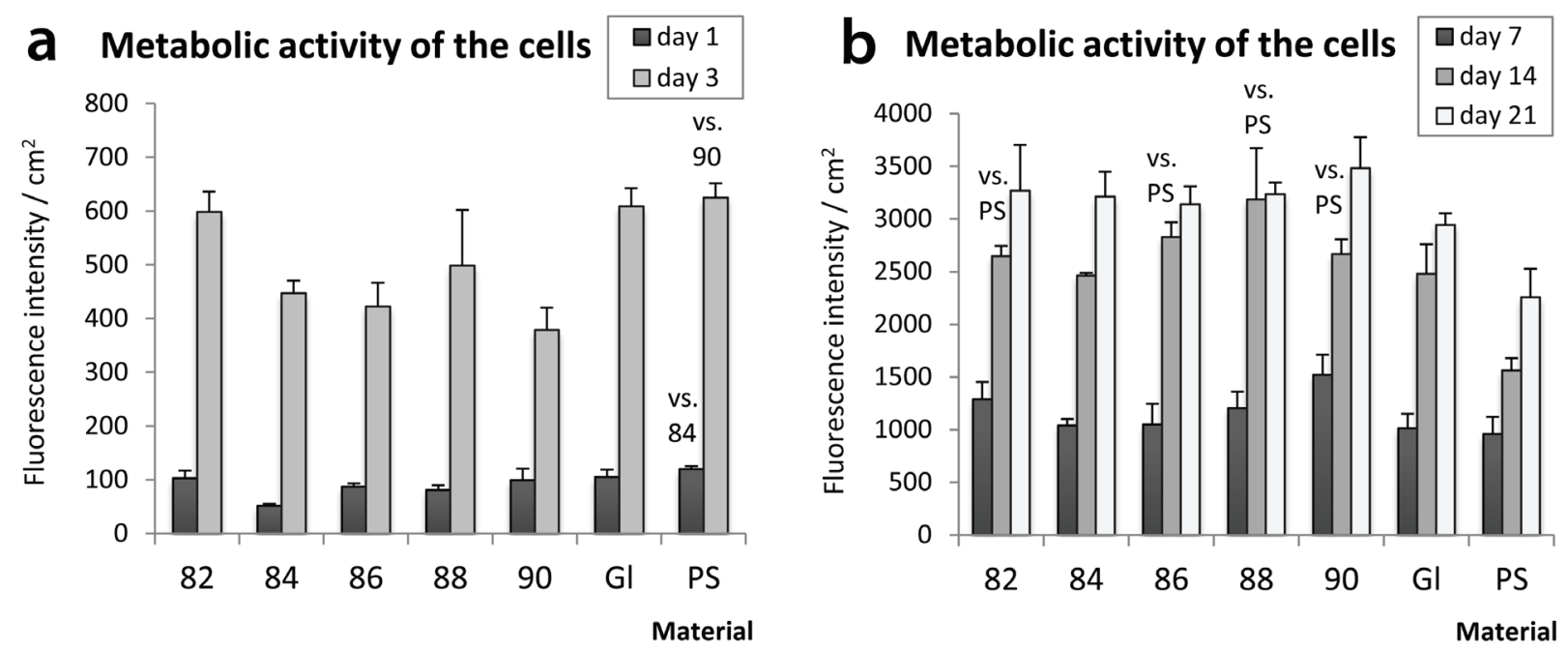

Fig. 2. Metabolic activity of hMSCs. The metabolic activity of hMSCs on a pure DLC layer (82) and on DLC layers doped with $0.9,1.8,7.3$ and 7.7 at.\% of $\mathrm{Cr}$ (84-90, respectively), on glass (Gl), and on cell culture polystyrene (PS) on day 1 and 3 (a), and on day 7, 14 and 21 (b), measured by incubating with resazurin for $4 \mathrm{~h}(\mathbf{a})$ and for $2.5 \mathrm{~h}(\mathbf{b})$. The data are expressed as mean \pm SEM, ANOVA, Student-Newman-Keuls method. The statistical significance $(p<0.05)$ is specified above the columns (compared to each sample on the same day of the culture).
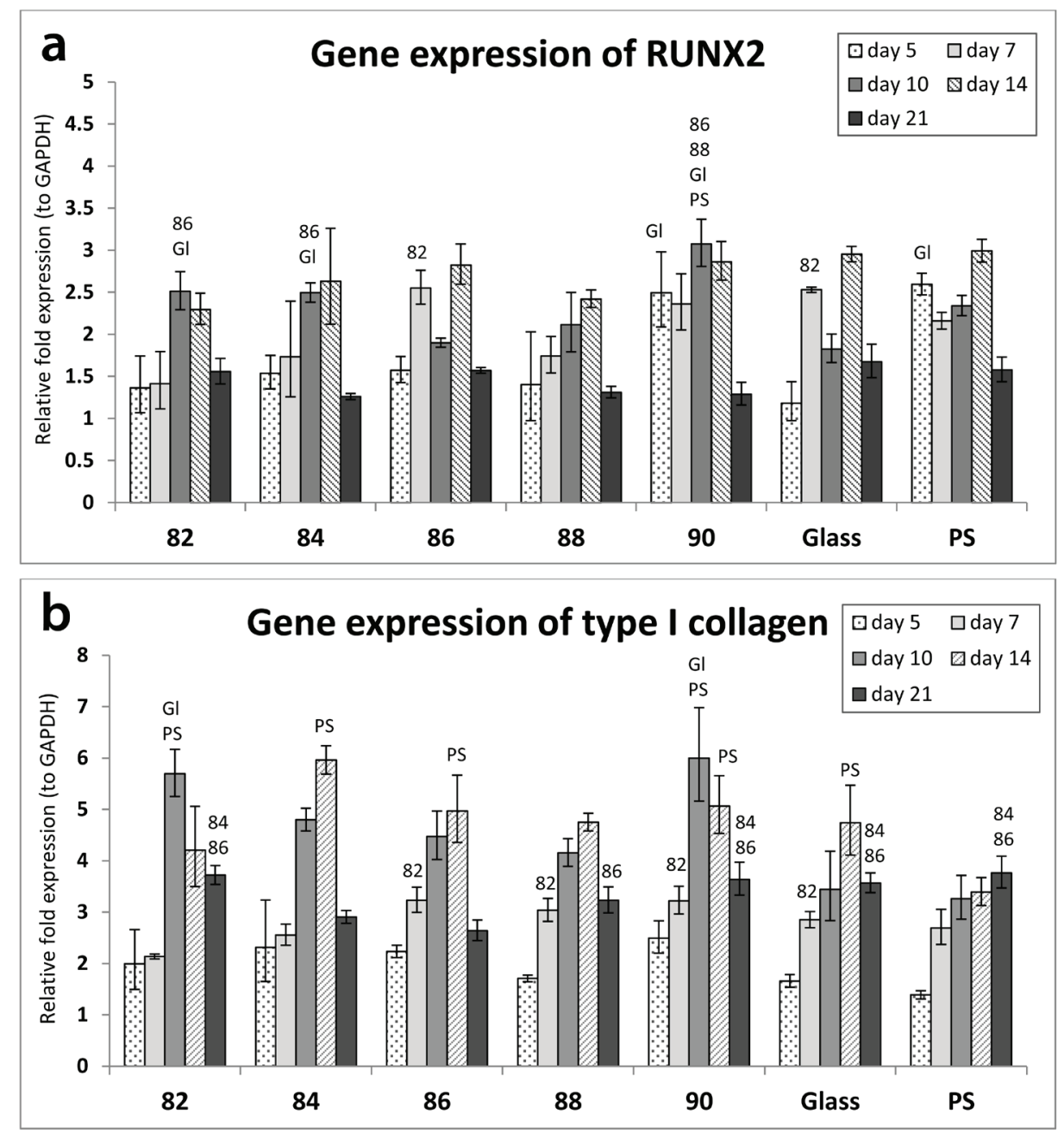

Fig. 3. Gene expression of RUNX2 and type I collagen. The gene expression of RUNX2 (a) and type I collagen $(\mathrm{Col})(\mathbf{b})$ in hMSCs on a pure DLC layer (82) and on DLC layers doped with $0.9,1.8,7.3$ and 7.7 at.\% of $\mathrm{Cr}$ (84-90, respectively), on glass, and on tissue culture polystyrene (PS) on days 5, 7, 10, 14 and 21 of the culture. Data are expressed as mean \pm SD. ANOVA, Student-Newman-Keuls method. The statistical significance $(p<0.01)$ is specified above the columns (compared to each sample on the same day of the culture). 
a similar increase over time in all samples. The maximum expression values were detected on days 10 or 14 , depending on the particular sample and on the particular gene. Although the general trend was similar, some significant differences appeared among the samples on specific days of the culture.

On day 5 , the gene expression of transcription factor RUNX2, a very early marker of osteogenic cell differentiation, was significantly higher in hMSCs on both sample 90 (i.e. DLC doped with 7.7 at.\% of $\mathrm{Cr}$ ) and on PS than on glass (Fig. 3a). On day 7, the highest RUNX2 expression was found in hMSCs on sample
86 (1.8 at.\% of $\mathrm{Cr}$ ) and on glass, with the values significantly higher than on sample 82 (pure DLC). On day 10, sample 90 (7.7 at.\% of $\mathrm{Cr}$ ) stimulated best the expression of RUNX2 in the hMSCs. On this sample, the RUNX2 expression values exceeded not only the values on glass, but also the values on the PS and DLC samples with lower Cr concentrations, namely samples 86 and 88, i.e. with 1.8 and 7.3 at.\% of $\mathrm{Cr}$, respectively. On the same day, the expression of RUNX2 in hMSCs on sample 86 was significantly lower than on samples 84 and 82, i.e. on DLC samples with the lowest concentration of $\mathrm{Cr}(0.9$ at.\%) and
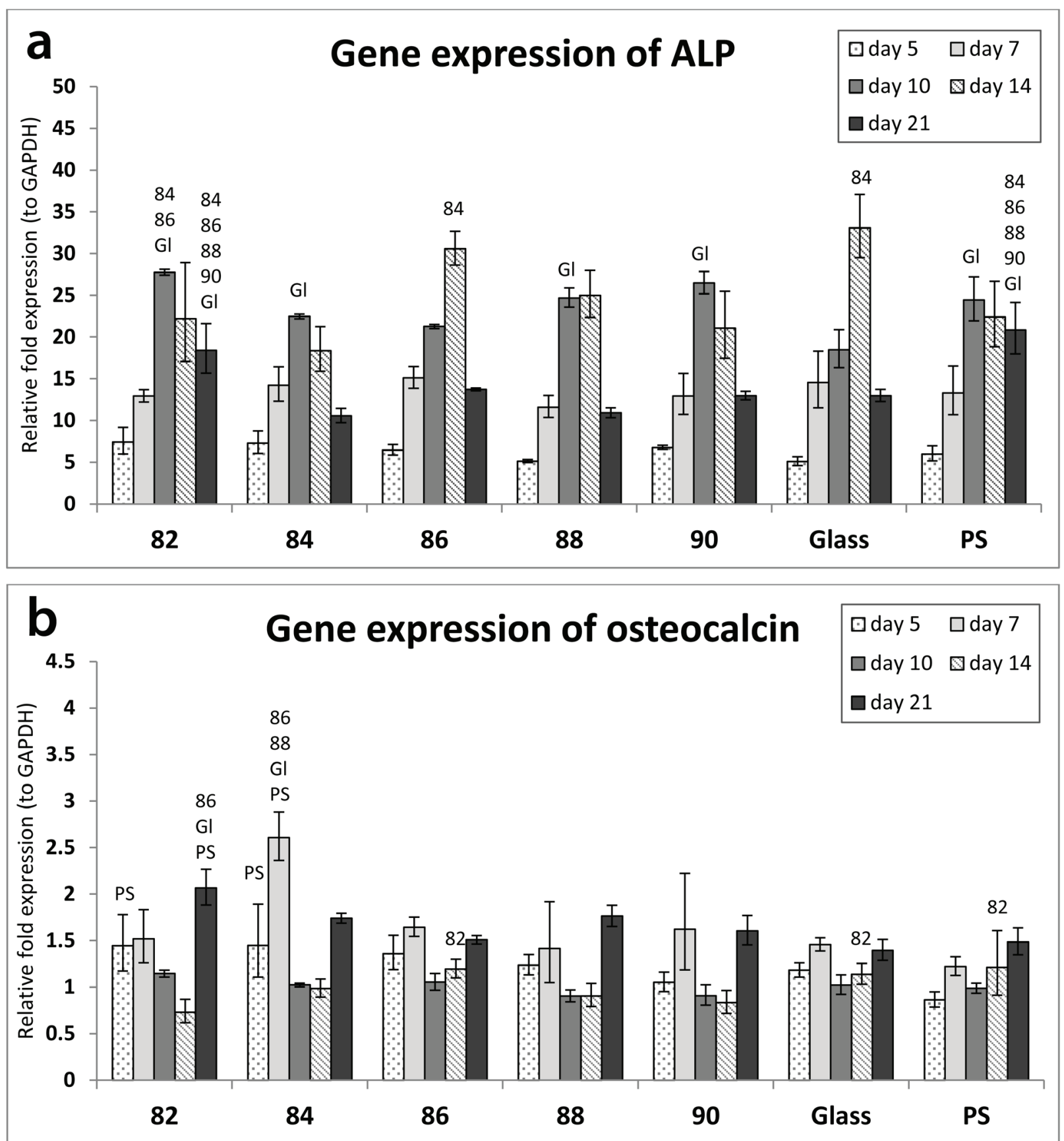

Fig. 4. Gene expression of ALP and osteocalcin. The gene expression of alkaline phosphatase (ALP) (a) and osteocalcin (b) in hMSCs on a pure DLC layer (82) and on DLC layers doped with $0.9,1.8,7.3$ and 7.7 at. \% of $\mathrm{Cr}$ (84-90, respectively), on glass, and on tissue culture polystyrene (PS) on days 5, 7, 10, 14 and 21 of the culture. Data are expressed as mean \pm SD. ANOVA, Student-Newman-Keuls method. The statistical significance $(p<0.01)$ is specified above the columns (compared to every sample on the same day of the culture). 
pure DLC, respectively (Fig. 3a). Between day 7 and day 14, the gene expression of RUNX2 increased with time on all samples except for sample 86 (1.8 at.\% of $\mathrm{Cr}$ ) and on glass. On day 21, the expression of RUNX2 in cells on all tested samples tended to decrease.

On day 5, the gene expression of type I collagen was similar in hMSCs on all DLC-based samples, Gl and PS (Fig. 3b). On day 7, increased levels of collagen expression were observed in hMSCs on samples 86, 88 and 90, i.e. with 1.8, 7.3, and 7.7 at.\% of $\mathrm{Cr}$, respectively, as well as on glass, than on sample 82, i.e. pure DLC. The highest expression of type I collagen gene was reached on days 10 and 14, depending on the specific samples. On day 10, the maximum expression was on samples 90 and 82, i.e., on DLC samples with 7.7 at.\% of Cr and on pure DLC, respectively, and this expression was significantly higher than on the control PS and on glass. On day 14, the expression of type I collagen also became higher on samples 84 and 86, i.e. DLC with 0.9 and 1.8 at.\% of $\mathrm{Cr}$, respectively, than on PS. On PS, however, the expression was rather low and slowly increasing, and did not reach its maximum until day 21. On day 21 , the gene expression of type I collagen decreased on the DLC samples, and the lowest values were detected on samples 84 and 86. Among DLC samples, sample 90 (7.7 at.\% of $\mathrm{Cr}$ ) caused a rapid onset of type I collagen expression in hMSCs, with the highest values measured even on day 10 .

On days 5 and 7, no significant differences in the expression of $A L P$ were observed among the tested samples (Fig. 4a). On day 10, the highest level of gene expression of $A L P$ was detected on sample 82, i.e. pure DLC, with its expression being higher than on samples 84,86 ( 0.9 and 1.8 at.\% of $\mathrm{Cr}$, respectively), and on glass. In addition, the ALP gene expression on samples 84,88 and 90, i.e. with $0.9,7.3$, and 7.7 at.\% $\mathrm{Cr}$, respectively, and on PS was significantly higher than on glass. On day 14, the highest expression of genes for $A L P$ was observed on sample 86 (1.8 at.\% of $\mathrm{Cr}$ ) and also on glass. On these samples, the ALP gene expression was significantly higher than on sample 84 (0.9 at.\% of $\mathrm{Cr}$ ). On day 21, the level of ALP expression decreased on all samples, but it still remained significantly higher on sample 82 (pure DLC) and on PS than on samples 84, 86, 88 and 90 (0.9 to 7.7 at. \% of $\mathrm{Cr}$ ), and glass.

The gene expression of osteocalcin (Fig. 4b), a late marker of osteogenic differentiation, showed only a mild increase in cells on several samples. On day 5 , the osteocalcin expression was higher in hMSCs cultured on samples 82 and 84, i.e. pure DLC and with 0.9 at.\% of Cr, respectively, than on PS. This trend continued to day 7, when the highest expression of osteocalcin was detected on sample 84 (0.9 at.\% of Cr). On day 21, the levels of gene expression of osteocalcin increased further on all samples; the highest value of osteocalcin expression was detected on sample 82 (i.e. pure DLC).

\section{Osteogenic differentiation on the protein level (immunofluorescence staining)}

On day 7 and 14 after seeding, the hMSC cells were positively stained both for the early marker (type I collagen; Fig. 5) and for the late marker (osteocalcin; Fig. 6) of osteogenic differentiation. A quantitative evaluation of images of fluorescence staining on day 7 revealed the highest fluorescence intensity of type I collagen (Fig. 7a) on sample 90 (7.7 at.\% of Cr).

In the case of osteocalcin, the highest fluorescence intensity was found on PS and also on sample 90 (7.7 at.\% of Cr) (Fig. 7b) on day 7. On day 14, as the photomicrographs were taken under the same exposure time, it was possible to observe the increase in fluorescence intensity of both type I collagen and osteocalcin. The highest fluorescence intensity of both osteogenic markers was detected on sample 84 (0.9 at.\% of $\mathrm{Cr}$ ). For osteocalcin, also on day 14, significantly higher fluorescence intensity per cell was attained on sample 90 (7.7 at.\% Cr) and also on glass than on sample 88 (7.3 at.\% of $\mathrm{Cr}$ ).

\section{Alkaline phosphatase (ALP) activity and calcium deposition}

On day 14, the ALP activity in cells on all samples was higher than on days 7 and 21 (Fig. 7c). However, there were no statistical differences $(p \leq 0.05)$ among the DLC-based samples and the control Gl and PS samples at each time interval.

The measurements of the deposition of calcium ions $\left(\mathrm{Ca}^{2+}\right)$ on day 14 (Fig. 7 d) showed no significant differences among the DLC-coated samples. A tendency towards a greater amount of $\mathrm{Ca}^{2+}$ ions on the control PS was observed; however, this difference was not significant due to the variability of the measured data on the PS samples. On day 21, the amount of deposited calcium had increased considerably on all samples, and the tendency towards higher $\mathrm{Ca}$ deposition on the control PS was still apparent (Fig. 7d). Nevertheless, there was no statistically significant difference $(p \leq 0.05)$ between the samples.

\section{Morphology, growth and cytokine production of macrophage-like cells}

The quantitative analysis of the spreading area in RAW 264.7 cells cultured with LPS showed increased cell spreading proportionally with increasing LPS concentration (Fig. 8a). The spreading area of RAW 264.7 cells reached similar values for all DLC-based samples, for the control glass samples (Gl), and for the cells grown in the lowest LPS concentration (i.e. $1 \mathrm{ng} / \mathrm{mL}$ of LPS) on PS. These values, however, were significantly higher than for the cells on the control PS without LPS (Fig. 8a). After LPS stimulation, the cells spread, contained vesicles in their cytoplasm (Fig. 8b-d) and their proliferation was lower on day 3 by $32.4 \%$ for $10 \mathrm{ng} / \mathrm{mL}$, by $26.0 \%$ for $100 \mathrm{ng} / \mathrm{mL}$, and by $51.0 \%$ for $1000 \mathrm{ng} / \mathrm{mL}$ of LPS than in the standard culture medium. On all DLC samples, on Gl and on PS without LPS, the RAW 264.7 cells were round, 


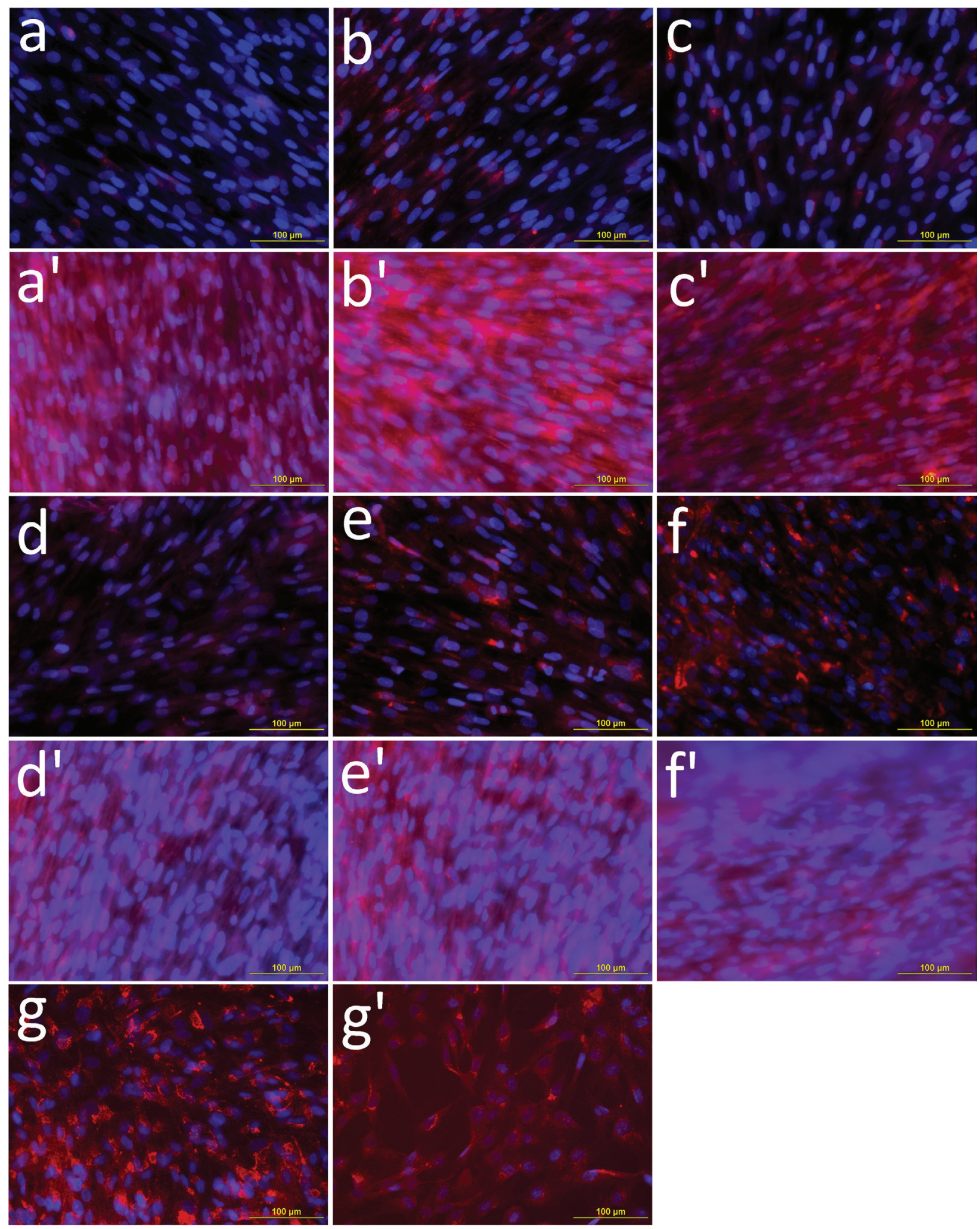

Fig. 5. Immunofluorescence staining of type I collagen. The immunofluorescence staining (red) of type I collagen in hMSCs on a pure DLC layer (82) $\left(\mathbf{a}, \mathbf{a}^{\prime}\right)$ and DLC layers doped with $0.9,1.8,7.3$ and 7.7 at.\% of Cr (84-90, respectively; $\left.\mathbf{b}, \mathbf{b}^{\prime}-\mathbf{e}, \mathbf{e}^{\prime}\right)$, on glass $\left(\mathbf{f}, \mathbf{f}^{\prime}\right)$, and on tissue culture polystyrene $\left(\mathbf{g}, \mathbf{g}^{\prime}\right)$ on day $7(\mathbf{a}-\mathbf{g})$ and on day $14\left(\mathbf{a}^{\prime}-\mathbf{g}^{\prime}\right)$. Cell nuclei are counterstained with Hoechst \#33258 (blue). Olympus IX 71 epifluorescence microscope, DP71 digital camera, objective $\times 20$. 


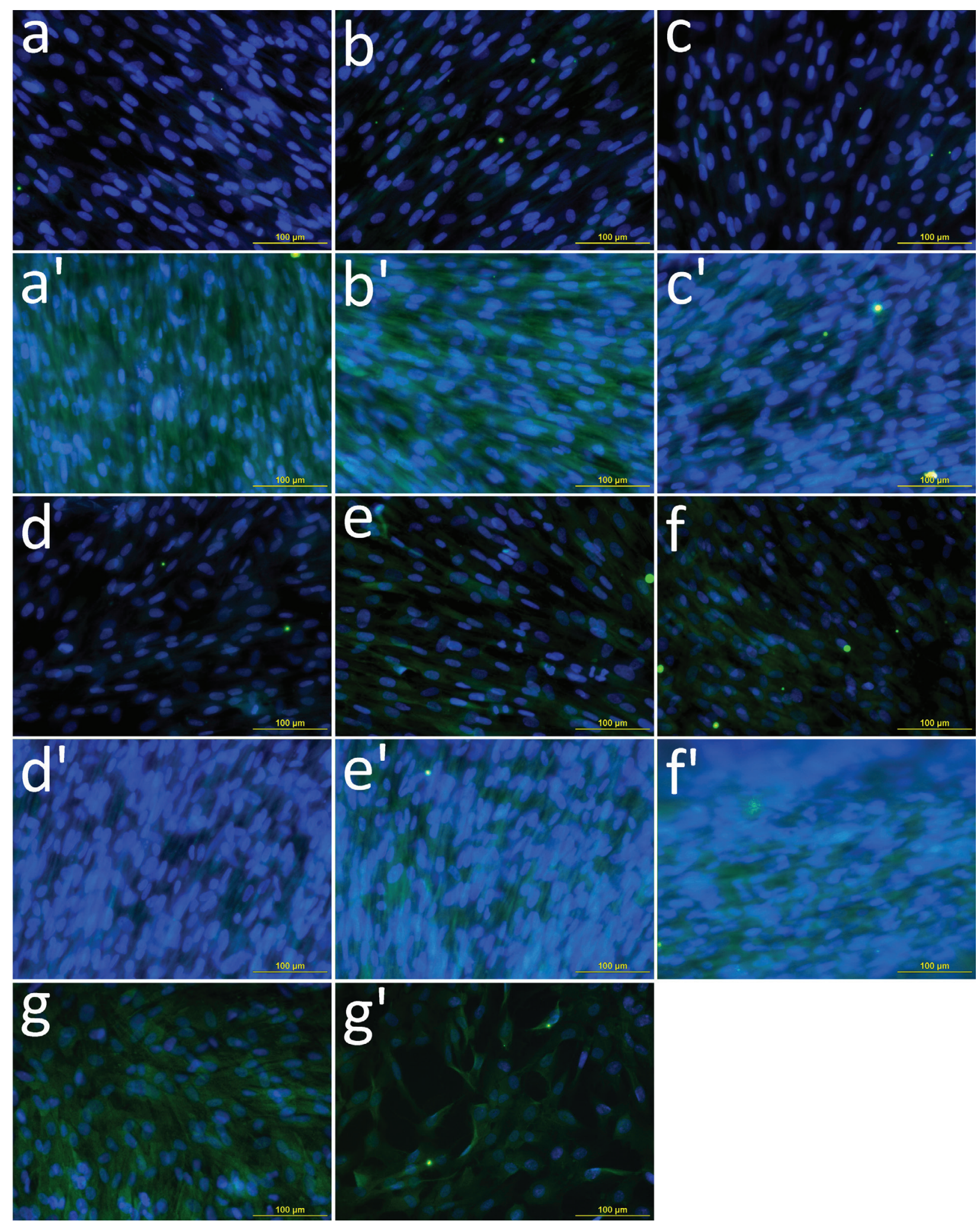

Fig. 6. Immunofluorescence staining of osteocalcin. The immunofluorescence staining (green) of osteocalcin in hMSCs on a pure DLC layer (82) (a, $\left.\mathbf{a}^{\prime}\right)$ and DLC layers doped with 0.9, 1.8, 7.3 and 7.7 at.\% of Cr (84-90, respectively; $\left.\mathbf{b}, \mathbf{b}^{\prime}-\mathbf{e}, \mathbf{e}^{\prime}\right)$, on glass $\left(\mathbf{f}, \mathbf{f}^{\prime}\right)$, and on tissue culture polystyrene $\left(\mathbf{g}, \mathbf{g}^{\prime}\right)$ on day 7 (a-g) and on day 14 $\left(\mathbf{a}^{\prime}-\mathbf{g}^{\prime}\right)$. Cell nuclei are counterstained with Hoechst \#33258 (blue). Olympus IX 71 epifluorescence microscope, DP71 digital camera, objective $\times 20$. 
weakly adhered (Fig. 8e-g) and their proliferation was similar to the value on the control sample, i.e. Gl (data not shown here).

The cytokine profile of the RAW 264.7 macrophages cultured on the Cr-doped DLC was assessed from the cell culture media on days 3 and 7, using the RayBio ${ }^{\mathrm{TM}}$ Human Cytokine Array for 40 cytokines. Table 3 shows that there were 18 cytokines with a value of two-fold or higher than the value for the positive control in the test. Generally, the cytokine production of RAW 264.7 cells on the DLC samples was very low. MIP-1 $\beta$ (CCL4) cytokine was present in the highest concentrations on day 3 , but these concentrations were lower on day 7 . The concentrations of all other cytokines depicted in Table 3 dropped from day 3 to day 7 to a value lower than 2. DLC doping with a higher $\mathrm{Cr}$ concentration caused a small increase in cytokine production on day 3 . The response of LPSstimulated RAW 264.7 cells was only measured on day 3 , but the values were higher than on the samples without LPS treatment. Surprisingly the values on PS were higher than on the DLC samples, but were still lower than on the LPS-supplemented samples.

\section{Fibroblast adhesion and proliferation}

On day 1 after seeding, the number of initially adhering NHDF cells was significantly lower on DLC samples 88 and 90, which contained 7.3 and 7.7 at.\% of $\mathrm{Cr}$, respectively, than on all the other samples (Fig. 9a). The cell number on day 3 , and the cell metabolic activity on day 7 were also lower on samples 88 and 90 (Fig. 9b-c).

\section{Apoptosis}

4 members of the Bcl-2 family were evaluated using qPCRs as markers of apoptosis. They included antiapoptotic BCL-XL protein, and pro-apoptotic Bax, Bim and Bid proteins. Apoptosis was induced in cells on Cr-doped DLC samples in order to examine the ability of these layers to have an anti-apoptotic

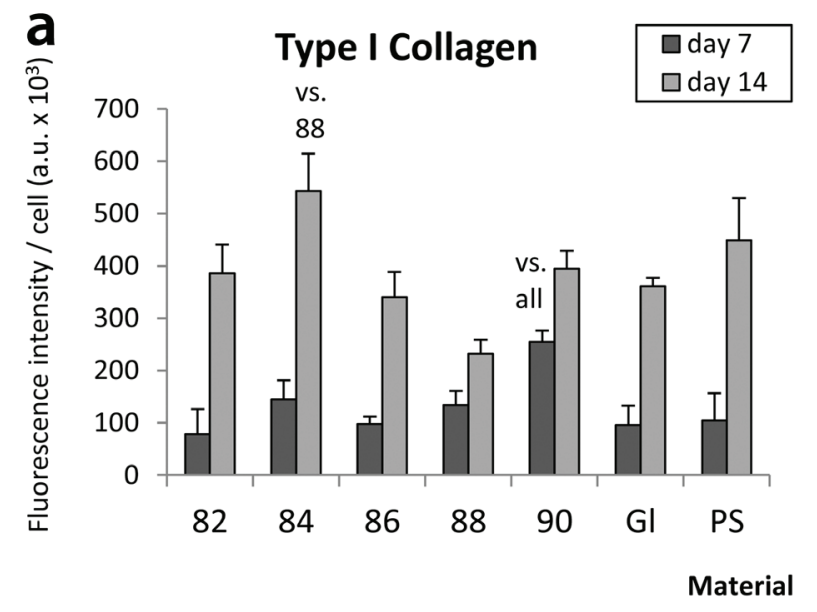

C Alkaline phosphatase activity

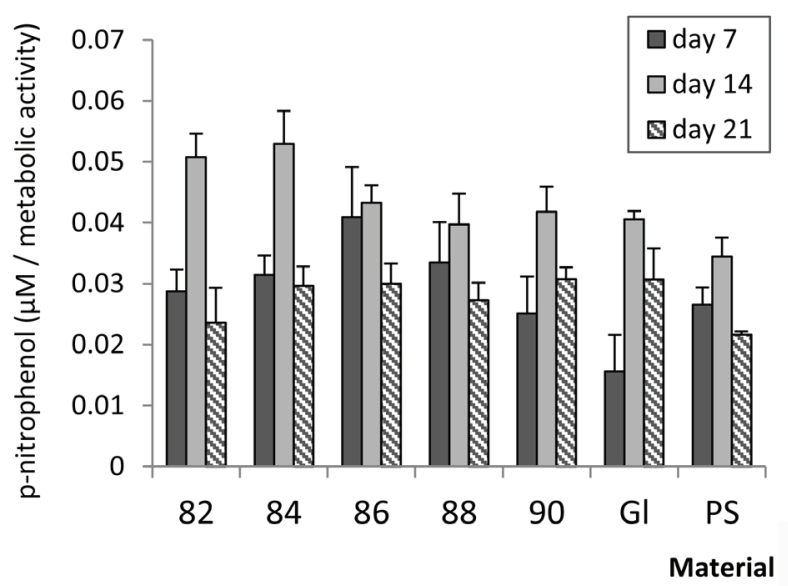

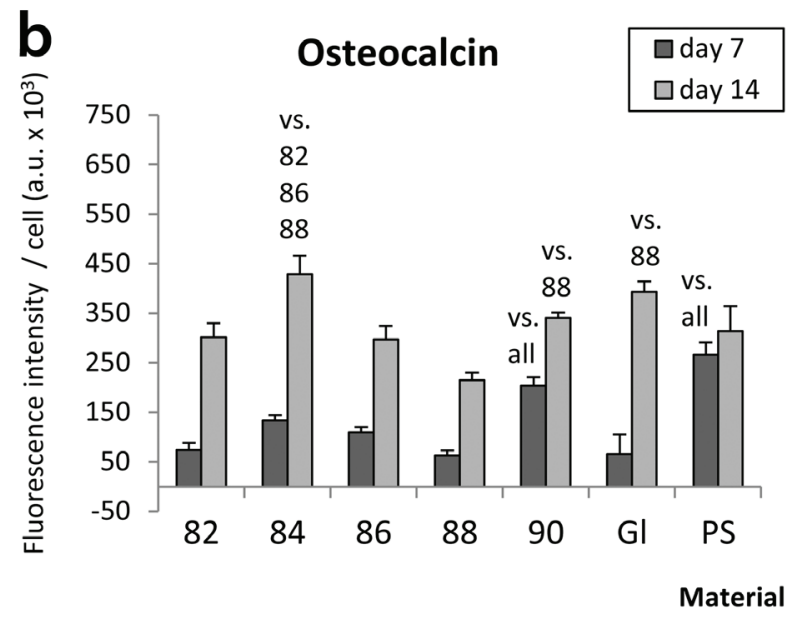

d Calcium deposition

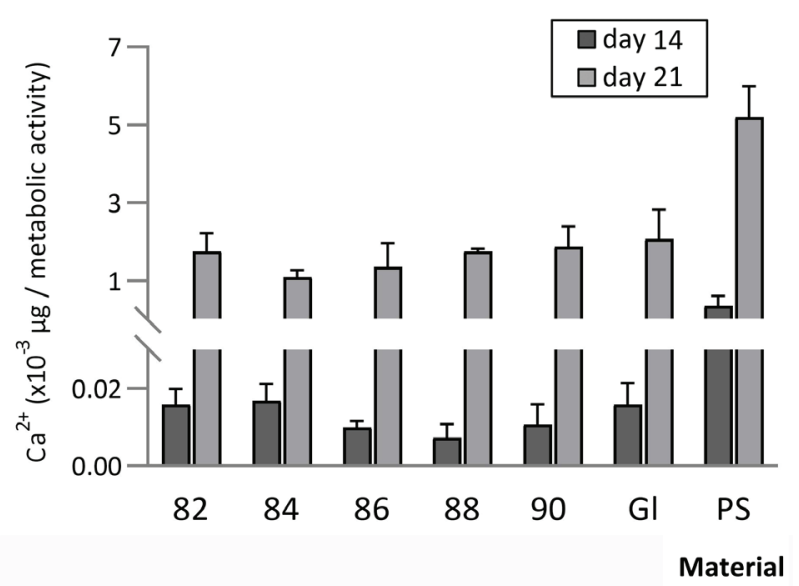

Fig. 7. Intensity of staining for type I collagen and osteocalcin, ALP activity, and calcium deposition. The fluorescence intensity of type I collagen (a) and osteocalcin (b), both normalised per cell, the ALP activity (c) and calcium deposition (d), both normalised per cell metabolic activity in hMSCs on a pure DLC layer (82) and DLC doped with 0.9, 1.8, 7.3 and 7.7 at.\% of Cr (84-90, respectively), on glass (Gl), on all samples a-d, and on polystyrene (PS, a-c) on days 7 and $14(\mathbf{a}, \mathbf{b}), 7,14$ and 21 (c), and on days 14 and 21 (d). All data are expressed as mean \pm SEM. ANOVA, Student-Newman-Keuls method. The statistical significance $(p<0.05)$ is specified above the columns (compared to each sample on the same day of the culture). 
or pro-apoptotic effect. For this purpose, apoptosis inducer camptothecin was used, which inhibits topoisomerase I and elicits apoptosis by a DNA damage pathway.

The response of Saos-2 cells, which were not treated with camptothecin, towards the presence of $\mathrm{Cr}$ in DLC samples was relatively weak and inconclusive. The gene expression of BCL-XL, an antiapoptotic factor, was higher on sample 88 (7.3 at.\% of $\mathrm{Cr}$ ) than on sample 90 (7.7 at.\% of $\mathrm{Cr}$ ) (Fig. 10a). The expression of Bax, a pro-apoptotic factor, was higher on all Cr-doped DLC samples than on pure DLC, but on the Cr-doped samples it still remained similar to the expression on the control PS and on glass (Fig. 10b). The expression of Bim was similar in the Saos-2 cells on all tested samples (Fig. 10c). Interestingly, the expression of Bid was higher on pure DLC and on DLC with 0.9 at.\% of $\mathrm{Cr}$ than on samples with 7.7 at.\% of $\mathrm{Cr}$ and on glass. After Saos-2 cells had been treated with camptothecin, the expression of BCL-XL was generally unchanged; the expression of Bax and Bim was increased, and the expression of Bid was mostly reduced in cells on all tested samples. The differences in cell response among the samples observed in camptothecin-free cultures disappeared (Fig. 10).

However, NHDF seemed to react more sensitively towards the presence of $\mathrm{Cr}$ in DLC layers (Fig. 11). Although the expression of anti-apoptotic BCL-XL was similar on all samples (Fig. 11a), the experiments revealed that the $\mathrm{Cr}$-doped DLC material with 7.3 and 7.7 at.\% of $\mathrm{Cr}$ increased the expression of pro-apoptotic factors (the white columns in Fig. 11). Specifically, the expression of Bax in cells on DLC samples 88 and 90 (i.e. with 7.3 and 7.7 at.\% of $\mathrm{Cr}$, respectively) became significantly higher (approximately doubled) than the value on PS (Fig. 11b). Similarly, the expression of Bim was significantly higher on all Cr-doped DLC samples than on glass, and the average values were highest on samples 88 and 90 (Fig. 11c). These findings were in agreement with the fibroblast cell number (Fig. 9), which was lower on the DLC samples with the highest $\mathrm{Cr}$ concentrations, i.e. 7.3 and 7.7 at.\% of $\mathrm{Cr}$. However, after a $48 \mathrm{~h}$ treatment with camptothecin, the fibroblasts acted in a reverse manner from that in the camptothecin-free cultures (the grey columns in Fig. 11). The expression of BCL-XL was lower on all DLC samples than on PS and on glass (Fig. 11a), with the lowest value found on sample 90 , i.e. on DLC with the highest $\mathrm{Cr}$ concentration of 7.7 at. $\%$ of $\mathrm{Cr}$. The expression of pro-apoptotic factors Bax, Bim and Bid was lowest in the cells on samples with the highest $\mathrm{Cr}$ concentrations, i.e. on samples 88 and 90 (Fig. 11b,c,d). This could be explained by the fact that camptothecin significantly increased the expression of Bax and Bim in the cells on the tested samples, with the exception of the samples doped with the highest Cr concentrations (Fig. 11b,c). The expression of Bid was lower on all Cr-doped DLC samples, and was

Table 3. Cytokine production on DLC. The production of selected cytokines by RAW 264.7 cells cultured on DLC containing $0 \% \mathrm{Cr}(82), 0.9 \% \mathrm{Cr}(84), 1.8 \% \mathrm{Cr}(86), 7.3 \% \mathrm{Cr}$ (88), $7.7 \% \mathrm{Cr}(90)$, and on glass, on days 3 and 7 after cell seeding, and the production of cytokines produced by RAW 264.7 cells cultured in cell culture medium supplemented with $10 \mathrm{ng} / \mathrm{mL}, 100 \mathrm{ng} / \mathrm{mL}$, and $1000 \mathrm{ng} / \mathrm{mL}$ of LPS on day 3 after cell seeding. Data are expressed as mean \pm SD. Colour legend: values $<2$ are marked white, 2-10, light green, 10-50, medium green, and $>50$, dark green.

\begin{tabular}{|c|c|c|c|c|c|c|c|c|c|c|}
\hline & Day & $\begin{array}{c}82 \\
(0 \% \mathrm{Cr}) \\
\end{array}$ & $\begin{array}{c}84 \\
(0.9 \% \mathrm{Cr}) \\
\end{array}$ & $\begin{array}{c}86 \\
(1.8 \% \mathrm{Cr}) \\
\end{array}$ & $\begin{array}{c}88 \\
(7.3 \% \mathrm{Cr}) \\
\end{array}$ & $\begin{array}{c}90 \\
(7.7 \% \mathrm{Cr}) \\
\end{array}$ & Glass & PS & $10 \mathrm{ng} / \mathrm{mL}$ LPS & $10^{3} \mathrm{ng} / \mathrm{mL}$ LPS \\
\hline IL-12p40 & $d 3$ & $3.40 \pm 0.21$ & $1.19 \pm 0.64$ & $7.27 \pm 0.58$ & $4.61 \pm 0.40$ & $6.03 \pm 0.45$ & $3.16 \pm 0.35$ & $6.46 \pm 0.10$ & $14.47 \pm 0.02$ & $17.18 \pm 2.22$ \\
\hline IL-12p70 & $d 3$ & $3.02 \pm 0.04$ & $2.27 \pm 0.39$ & $5.87 \pm 0.67$ & $3.36 \pm 0.13$ & $4.73 \pm 0.06$ & $2.85 \pm 0.24$ & $4.56 \pm 0.99$ & $9.08 \pm 0.84$ & $13.07 \pm 2.98$ \\
\hline IL-1 $\alpha$ & $d 3$ & $6.12 \pm 0.29$ & $6.90 \pm 1.54$ & $12.89 \pm 1.11$ & $9.94 \pm 1.35$ & $10.21 \pm 0.70$ & $7.22 \pm 0.68$ & $3.32 \pm 1.82$ & $6.87 \pm 0.81$ & $13.12 \pm 2.96$ \\
\hline IL-1 $\beta$ & $d 3$ & $0.36 \pm 0.51$ & $3.26 \pm 0.46$ & $1.96 \pm 0.15$ & $2.64 \pm 0.80$ & $3.55 \pm 0.02$ & $2.76 \pm 0.36$ & $4.88 \pm 1.23$ & $6.05 \pm 0.66$ & $3.18 \pm 3.50$ \\
\hline IP-10 & $d 3$ & $5.68 \pm 0.36$ & $8.23 \pm 0.11$ & $6.93 \pm 0.36$ & $8.04 \pm 0.22$ & $8.99 \pm 1.15$ & $6.69 \pm 0.02$ & $32.74 \pm 1.69$ & $39.00 \pm 1.95$ & $37.01 \pm 8.44$ \\
\hline MIP-1 $1 \alpha$ & $d 3$ & $3.63 \pm 0.11$ & $2.22 \pm 0.68$ & $5.21 \pm 0.86$ & $3.99 \pm 0.04$ & $4.53 \pm 0.31$ & $3.73 \pm 0.05$ & $9.48 \pm 0.95$ & $13.39 \pm 0.75$ & $17.29 \pm 0.22$ \\
\hline \multirow[t]{2}{*}{ MIP-1 $\beta$} & $d 3$ & $19.42 \pm 0.25$ & $14.37 \pm 0.43$ & $30.87 \pm 2.38$ & $26.89 \pm 0.04$ & $25.76 \pm 4.17$ & $19.45 \pm 1.13$ & $44.12 \pm 2.87$ & $78.67 \pm 0.76$ & $105.33 \pm 5.25$ \\
\hline & $d 7$ & $8.69 \pm 0.14$ & $5.15 \pm 1.04$ & $8.09 \pm 0.27$ & $4.61 \pm 0.04$ & $4.41 \pm 0.75$ & $6.20 \pm 0.17$ & & & \\
\hline MIP-1ठ & $d 3$ & $2.71 \pm 0.15$ & $1.43 \pm 0.13$ & $3.54 \pm 0.88$ & $2.03 \pm 0.82$ & $1.92 \pm 1.00$ & $1.68 \pm 0.72$ & $7.18 \pm 0.77$ & $14.59 \pm 1.80$ & $20.95 \pm 3.16$ \\
\hline RANTES & $d 3$ & $1.91 \pm 0.56$ & $4.69 \pm 0.54$ & $3.59 \pm 0.77$ & $4.82 \pm 0.33$ & $6.40 \pm 0.35$ & $5.02 \pm 0.09$ & $31.38 \pm 2.11$ & $49.43 \pm 5.35$ & $51.40 \pm 17.58$ \\
\hline sTNFRII & $d 3$ & $4.90 \pm 0.70$ & $5.25 \pm 0.71$ & $4.64 \pm 0.08$ & $6.53 \pm 0.27$ & $6.60 \pm 0.23$ & $5.90 \pm 0.23$ & $4.39 \pm 0.03$ & $6.17 \pm 1.42$ & $5.48 \pm 1.61$ \\
\hline IL-3 & $d 3$ & $2.18 \pm 0.26$ & $3.01 \pm 0.61$ & $3.44 \pm 0.69$ & $2.78 \pm 0.51$ & $4.42 \pm 0.00$ & $3.19 \pm 0.00$ & $15.61 \pm 2.11$ & $27.48 \pm 2.22$ & $24.43 \pm 1.57$ \\
\hline M-CSF & $d 3$ & $3.29 \pm 0.23$ & $2.82 \pm 0.16$ & $3.19 \pm 0.33$ & $3.61 \pm 0.22$ & $4.80 \pm 0.39$ & $3.49 \pm 0.03$ & $25.05 \pm 5.58$ & $30.10 \pm 1.09$ & $32.36 \pm 1.87$ \\
\hline TNF- $\beta$ & $d^{3}$ & $1.75 \pm 0.11$ & $3.08 \pm 0.11$ & $1.95 \pm 0.33$ & $3.03 \pm 0.07$ & $2.73 \pm 0.27$ & $3.16 \pm 0.47$ & $16.21 \pm 4.03$ & $16.36 \pm 2.5$ & $24.69 \pm 2.32$ \\
\hline ICAM-1 & $d^{3}$ & $2.39 \pm 0.14$ & $2.34 \pm 0.45$ & $5.09 \pm 0.13$ & $2.51 \pm 0.36$ & $4.39 \pm 0.94$ & $3.10 \pm 0.57$ & $5.59 \pm 0.25$ & $8.19 \pm 1.55$ & $7.78 \pm 0.39$ \\
\hline $\mathrm{I}-309$ & $d 3$ & $1.67 \pm 0.16$ & $1.05 \pm 0.34$ & $3.93 \pm 0.58$ & $2.51 \pm 0.36$ & $2.97 \pm 0.61$ & $1.89 \pm 0.48$ & $2.26 \pm 0.58$ & $3.85 \pm 0.34$ & $8.52 \pm 1.65$ \\
\hline Eotaxin & $d 3$ & $1.52 \pm 0.01$ & $2.41 \pm 0.30$ & $3.66 \pm 0.21$ & $2.59 \pm 0.02$ & $3.42 \pm 0.20$ & $3.17 \pm 0.24$ & $4.25 \pm 0.14$ & $6.73 \pm 1.03$ & $7.99 \pm 0.34$ \\
\hline Eotaxin-2 & $d^{2} 3$ & $1.79 \pm 0.29$ & $2.73 \pm 0.57$ & $4.68 \pm 0.27$ & $3.22 \pm 0.24$ & $4.75 \pm 0.70$ & $4.37 \pm 0.80$ & $19.76 \pm 0.40$ & $34.34 \pm 3.62$ & $33.32 \pm 4.00$ \\
\hline TGF- $\beta 1$ & $d 3$ & $1.22 \pm 0.36$ & $2.60 \pm 0.29$ & $2.05 \pm 0.52$ & $3.25 \pm 0.29$ & $3.78 \pm 0.43$ & $2.72 \pm 0.15$ & $0.12 \pm 0.17$ & $2.91 \pm 0.04$ & $6.17 \pm 3.41$ \\
\hline
\end{tabular}

\begin{tabular}{l|l|l|l|}
$<2$ & $2-10$ & $10-50$ & $>50$ \\
\hline
\end{tabular} 

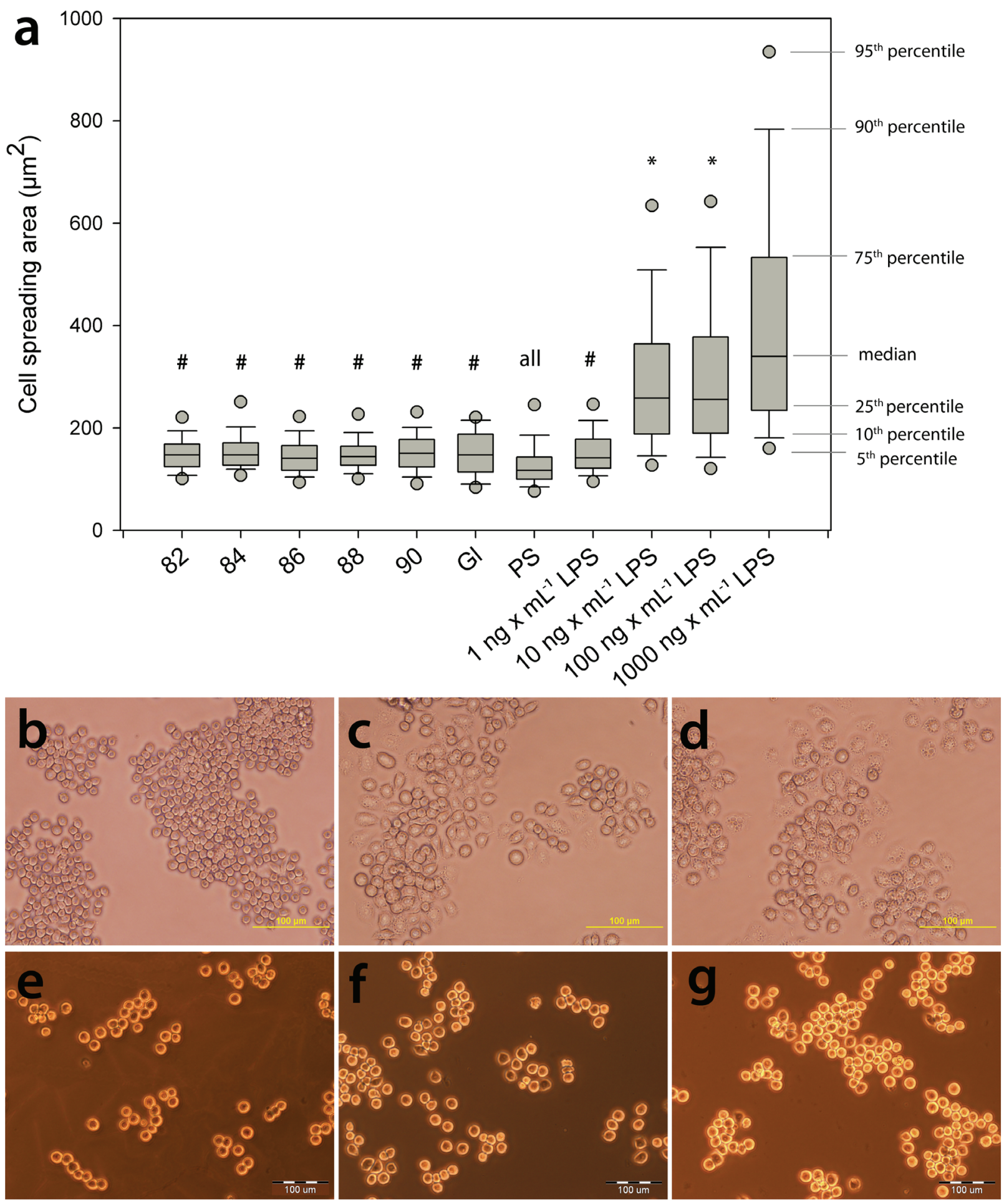

Fig. 8. Cell spreading area and morphology of RAW 264.7 cells. The cell spreading area (a) of RAW 264.7 cells on day 3 of the culture on a pure DLC layer (82) and on DLC layers doped with 0.9, 1.8, 7.3 and 7.7 at.\% of Cr (84-90, respectively), on glass (Gl), on tissue culture polystyrene (PS), and on PS with LPS (concentration from $1 \mathrm{ng} / \mathrm{mL}$ to $1,000 \mathrm{ng} / \mathrm{mL}$ of LPS). The data are presented in box plots with explanatory notes on the right border of the plot. ANOVA on Ranks, Dunn's method. Statistical significance $(p<0.05)$ is specified above the columns. "all" - significantly less than all other samples; \# - significantly less than $10 \mathrm{ng} / \mathrm{mL}$ LPS, $100 \mathrm{ng} /$ mL LPS, and 1,000 ng/mL LPS; * - significantly less than 1,000 ng/mL LPS. The morphology of RAW 264.7 cells on day 3 of the culture on PS treated with no LPS (b), with $10 \mathrm{ng} / \mathrm{mL}$ of LPS (c) and with 1,000 ng/mL of LPS (d). The morphology of RAW 264.7 cells without the LPS treatment on pure DLC (e), on DLC with 1.8 at. $\%$ of $\mathrm{Cr}(\mathbf{f})$ and on DLC with 7.7 at. \% of $\mathrm{Cr}(\mathbf{g})$. Olympus IX51 epifluorescence microscope, DP70 digital camera, objective $\times 20$, scale bar $=100 \mu \mathrm{m}$. 
higher only on the control PS and on the glass samples (Fig. 11d). These results suggested that chromium in DLC layers could induce apoptosis and weaken the cells, so that they were not able to respond more intensively to camptothecin treatment.

Table 4 shows the results of flow cytometry analysis of the PI/annexin V labelling assay for detecting apoptosis in cultures of NHDF and osteoblast-like Saos-2 cells. Cells treated with camptothecin $(4 \mu \mathrm{g} / \mathrm{mL})$ for $48 \mathrm{~h}$ served as a positive control. The percentage of measured cells was counted from gated quartiles where the vital cells were negative for both PI and annexin V, apoptotic cells were PI negative and annexin $\mathrm{V}$ positive, while dead cells considered as necrotic were positive for both PI and annexin V. The number of both apoptotic and necrotic fibroblasts in camptothecin-free cultures showed a tendency to be higher on DLC with higher Cr concentrations (i.e. 7.3 and 7.7 at.\%) than on DLC with lower $\mathrm{Cr}$ concentrations. However, the values were not higher than on the control samples (Glass and PS). In Saos- 2 cells, these differences were much less apparent. After exposure to camptothecin, the proportion of both apoptotic and necrotic NHDF increased dramatically. In addition, the fraction of necrotic cells in the NHDF culture increased slightly with increasing Cr content. In experiments with Saos2 cells after camptothecin stimulation, the proportion of necrotic cells increased much more apparently than the proportion of apoptotic cells. The percentage of apoptotic Saos-2 cells increased predominantly on DLC samples, and less on PS.

\section{Discussion}

\section{The adhesion, growth and osteogenic} differentiation of hMSCs

The biocompatibility of DLC layers has been confirmed in numerous in vitro and in vivo studies (Allen et al., 2001; Liao et al., 2016). Soininen et al. (2014) modified DLC with polydimethylsiloxane hybrid (DLC-PDMS-h), as a potential coating for non-integrating implants for temporary use (Soininen et al., 2014). This study confirmed poor cell adhesion and low osteogenic differentiation of hMSCs on DLC-PDMS-h in comparison with DLC or Ti. In another study, DLC coating attenuated the toxicity of NiTi alloy for dental application by reducing the concentration of the released $\mathrm{Ni}$ ions after $14 \mathrm{~d}$ and 6 months of immersion in physiological saline (Kobayashi et al., 2007). Stiehler et al. (2008) studied the effect of smooth surfaces of pure $\mathrm{Ti}$, Ta and $\mathrm{Cr}$ on hMSC attachment, proliferation and osteogenic differentiation. The authors found that a smooth surface of pure $\mathrm{Cr}$ had a lower supportive effect on cell attachment and proliferation than a smooth surface of Ti or Ta. However, mRNA analysis of osteogenic markers showed higher upregulation of these markers in hMSCs exposed to a Cr surface (Stiehler et al., 2008).
In the present study, the adhesion, growth and osteogenic differentiation of hMSCs was investigated on Cr-doped DLC with different contents of Cr. On day 1, more apparent vinculin-containing focal adhesion plaques were observed on samples with a higher $\mathrm{Cr}$ content (i.e. 7.3 at.\% for sample 88, and 7.7 at.\% for sample 90). This indicated better cell adhesion and signalling via integrin receptors in samples with higher $\mathrm{Cr}$ content. This was in accordance with a previous study, in which better spreading of Saos-2 cells was observed on DLC with a higher $\mathrm{Cr}$ content, with the maximum value obtained on DLC with 7.7 at.\% of Cr (Filova et al.,

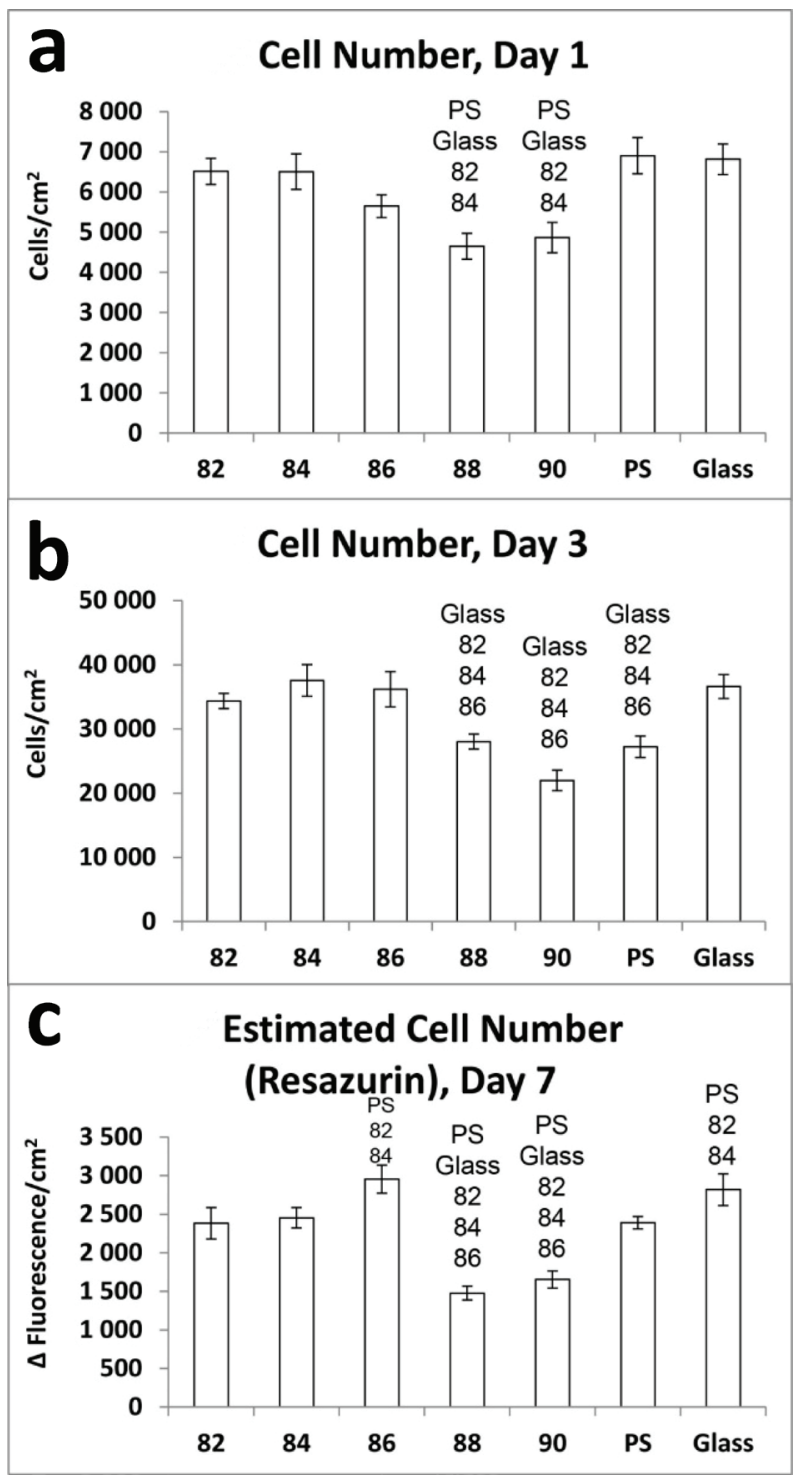

Fig. 9. Cell density and metabolic activity of NHDFs. Cell densities of NHDFs on day 1 (a) and day 3 (b) and metabolic activity of NHDFs on day 7 (c) on pure DLC (82), DLC with 0.9 at. \% of $\mathrm{Cr}(84)$, DLC with 1.8 at.\% of $\mathrm{Cr}$ (86), DLC with 7.3 at.\% of $\mathrm{Cr}$ (88), DLC with 7.7 at.\% of Cr (90), on tissue culture polystyrene (PS), and on glass. Data are expressed as mean \pm S.E.M. ANOVA, Student-Newman-Keuls method. The statistical significance $(p<0.05)$ in comparison with the other samples is specified above the columns. 
Table 4. Flow cytometry analysis of annexin $\mathrm{V}$ staining. The percentage of apoptotic and necrotic cells in NHDFs and Saos-2 culture with or without camptothecin treatment on pure DLC (82), DLC with 0.9 at. \% of $\mathrm{Cr}$ (84), DLC with 1.8 at.\% of Cr (86), DLC with 7.3 at.\% of Cr (88), DLC with 7.7 at.\% of Cr (90), glass (Gl) and on tissue culture polystyrene (PS). The flow cytometry analysis was performed $48 \mathrm{~h}$ after camptothecin treatment.

\begin{tabular}{|l|l|r|r|r|r|r|r|r|}
\hline & & \multicolumn{1}{|c|}{$\mathbf{8 2}$} & \multicolumn{1}{c|}{$\mathbf{8 4}$} & \multicolumn{1}{c|}{$\mathbf{8 6}$} & $\mathbf{8 8}$ & $\mathbf{9 0}$ & \multicolumn{1}{c|}{ Glass } & \multicolumn{1}{c|}{ PS } \\
\hline \multirow{2}{*}{ NHDF } & \% of apoptotic cells & 1.16 & 2.47 & 1.30 & 3.76 & 3.64 & 3.80 & 4.44 \\
& \% of necrotic cells & 1.27 & 2.96 & 1.45 & 4.58 & 6.43 & 3.65 & 5.88 \\
\hline \multirow{2}{*}{ NHDF + camptothecin } & \% of apoptotic cells & 23.91 & 25.62 & 26.43 & 22.56 & 16.18 & 48.11 & 35.21 \\
& \% of necrotic cells & 63.36 & 66.88 & 67.33 & 69.25 & 78.06 & 41.26 & 53.51 \\
\hline \multirow{2}{*}{ Saos-2 } & \% of apoptotic cells & 3.24 & 2.79 & 3.39 & 3.95 & 3.46 & 2.70 & 5.10 \\
& \% of necrotic cells & 8.24 & 7.56 & 8.34 & 8.88 & 10.08 & 6.28 & 14.86 \\
\hline \multirow{2}{*}{ Saos-2 + camtothecin } & \% of apoptotic cells & 6.88 & 7.44 & 10.13 & 8.80 & 9.55 & 9.64 & 5.89 \\
& \% of necrotic cells & 60.40 & 64.39 & 58.63 & 58.42 & 60.02 & 51.28 & 64.66 \\
\hline
\end{tabular}

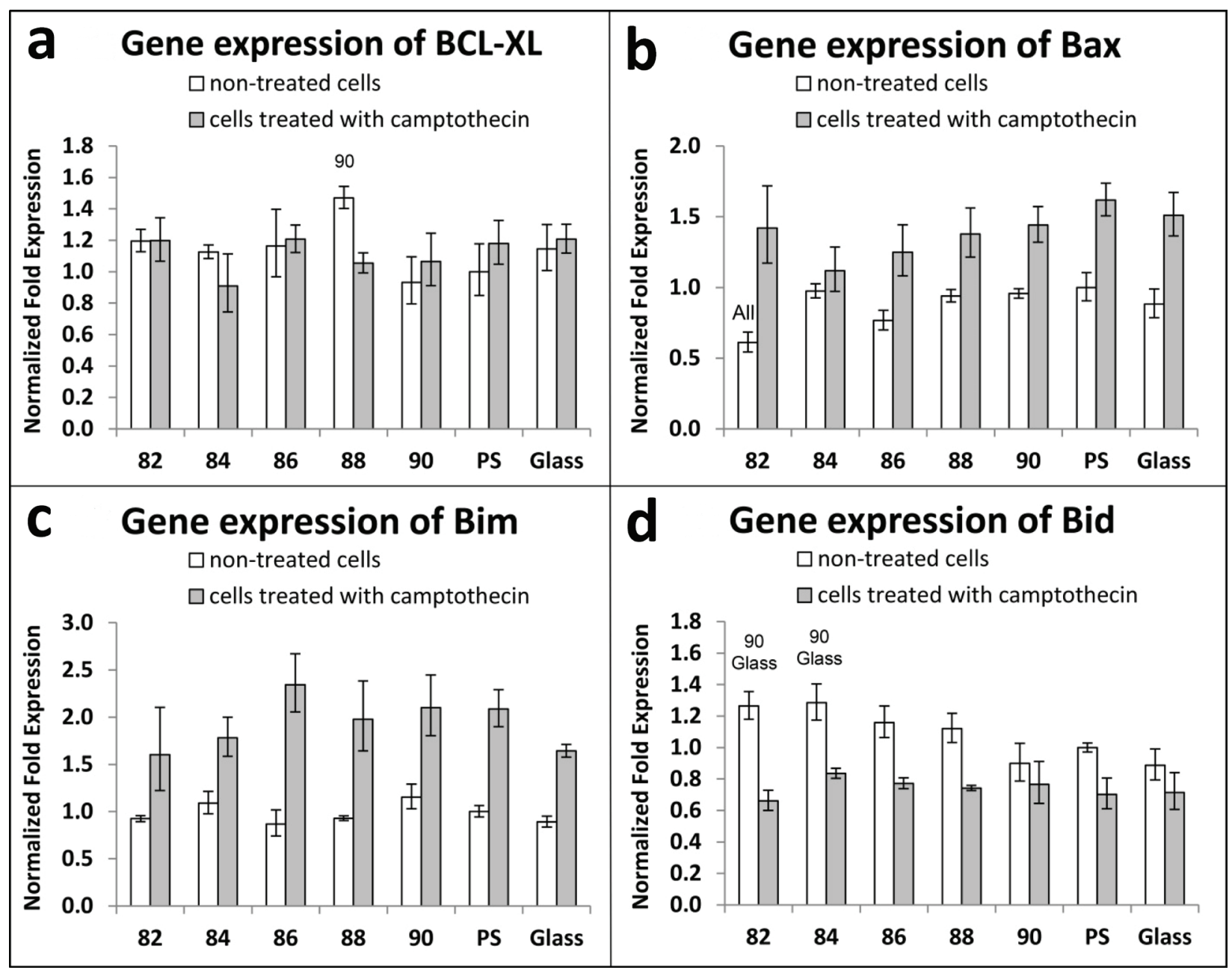

Fig. 10. Apoptosis, gene expression in Saos-2 cells. Gene expression of $B C L-X L(\mathbf{a}), \operatorname{Bax}(\mathbf{b}), \operatorname{Bim}(\mathbf{c})$ and $\operatorname{Bid}$ (d) in Saos-2 cells on day 9 after seeding (white columns) and in Saos-2 cells on day 9 after seeding and $2 \mathrm{~d}$ of stimulation with camptothecin (grey columns) on pure DLC (82), DLC with 0.9 at.\% of Cr (84), DLC with 1.8 at.\% of $\mathrm{Cr}$ (86), DLC with 7.3 at.\% of $\mathrm{Cr}$ (88), DLC with 7.7 at.\% of $\mathrm{Cr}(90)$, on tissue culture polystyrene (PS) and on glass. Data are expressed as mean \pm SD. ANOVA, Student-Newman-Keuls method. The statistical significance $(p<0.05)$ is specified above the columns compared to the samples with the same treatment. 
2017). In addition, Saos-2 cells developed apparent vinculin-containing focal adhesion plaques on $\mathrm{Cr}$ doped DLC, with significantly higher fluorescence intensity of staining on all DLC samples other than on glass. The better formation of focal adhesion plaques by cells on DLC with higher $\mathrm{Cr}$ content may be attributed to the surface nanostructure of $\mathrm{Cr}$ doped DLC. An AFM evaluation (Filova et al., 2017) showed that the surfaces of both pure DLC and DLC with 0.9 at. \% of $\mathrm{Cr}$ were almost flat, with sporadic peaks of about $40 \mathrm{~nm}$ in height. DLC surfaces with a higher $\mathrm{Cr}$ content, i.e. 7.3 at.\% and 7.7 at.\% of $\mathrm{Cr}$ were continuously and regularly covered with fine nanoscale structures with sporadic taller peaks that were $14 \mathrm{~nm}$ in height (Filova et al., 2017). The Sa parameter measured from a $50 \times 50 \mu \mathrm{m}^{2}$ area was $1.1 \mathrm{~nm}$ for pure DLC, $3.61 \mathrm{~nm}$ for 0.9 at.\% of $\mathrm{Cr}, 1.18 \mathrm{~nm}$ for 7.3 at.\% of $\mathrm{Cr}$, and $1.24 \mathrm{~nm}$ for 7.7 at.\% of Cr (Filova et al., 2017).

Nanoroughness significantly influences the cell-material interaction by modifying the protein adsorption. In a study by Rockwell et al. (2012), the adsorption of both fibrinogen and albumin on $\mathrm{Ti}$ increased proportionally to the surface nanoroughness for RMS in the range of $0-10 \mathrm{~nm}$. There was a maximum value at about $10 \mathrm{~nm}$ and then the adsorption stagnated up to an RMS value of $17 \mathrm{~nm}$. Nevertheless, on days 7, 14 and 21, the metabolic activity of hMSCs improved on Cr-doped DLC to a similar level or even to a higher level than on the control PS and glass samples. On nanostructured surfaces, the adsorption of extracellular matrix proteins mediating cell adhesion, e.g. fibronectin, vitronectin, and type I collagen, is also higher (Webster et al., 2000). In addition, these molecules are adsorbed in an advantageous geometrical conformation, which supports binding cells through their adhesion receptors, which are then clustered into focal adhesion sites. In a previous study with Ti-6Al-4V nanotubes, Saos-2 cells adhered at a similar density on nanotubes of different sizes and developed well-formed focal adhesions, but there was a stronger signal for vinculin and talin in the cells

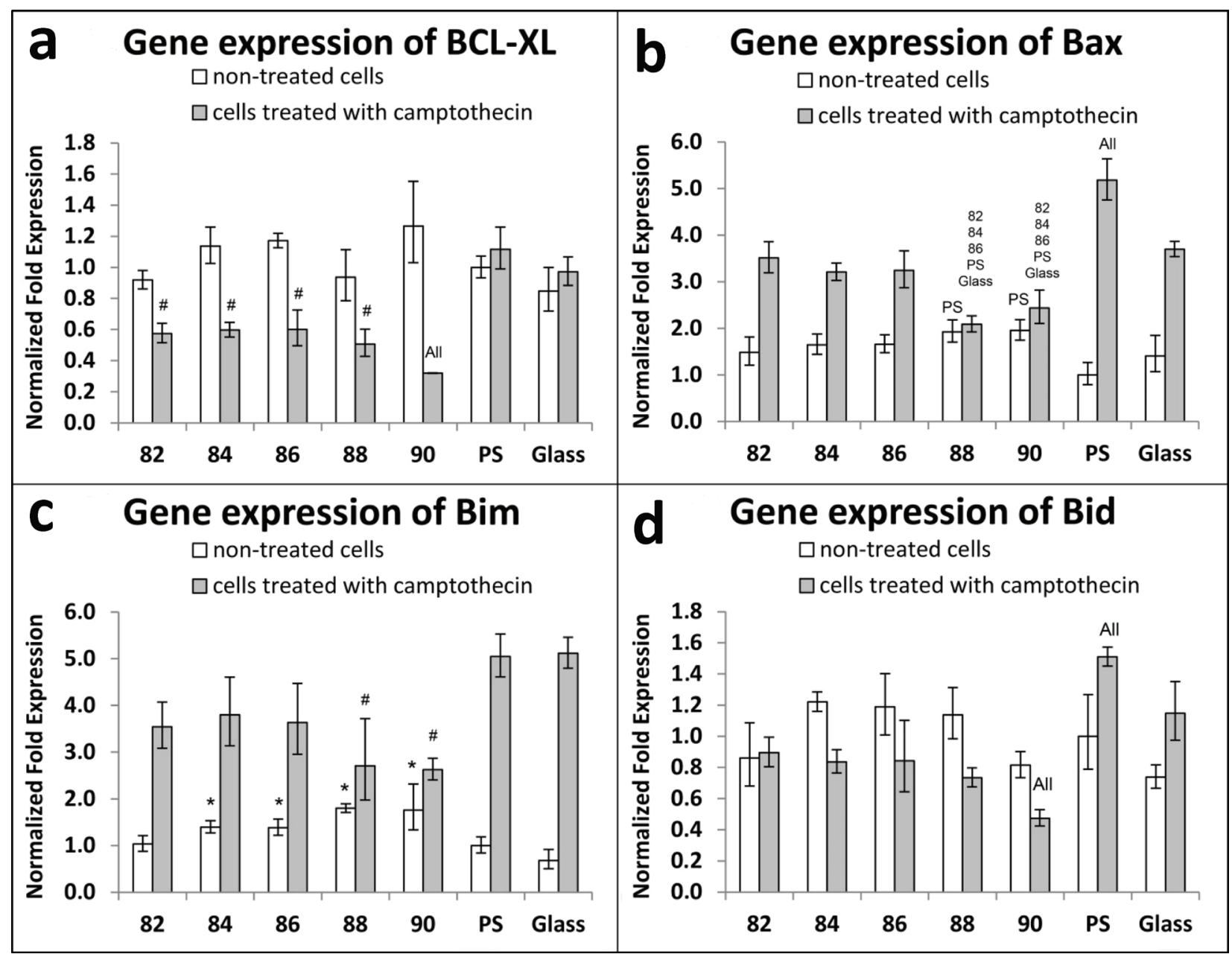

Fig. 11. Apoptosis, gene expression in NHDF cells. Gene expression of BCL-XL (a), Bax (b), Bim (c) and Bid (d) in NHDF cells on day 9 after seeding (white columns) and in NHDF cells on day 9 after seeding and $2 \mathrm{~d}$ of stimulation with camptothecin (grey columns) on pure DLC (82), DLC with 0.9 at.\% of Cr (84), DLC with 1.8 at.\% of Cr (86), DLC with 7.3 at.\% of Cr (88), DLC with 7.7 at.\% of Cr (90), on tissue culture polystyrene (PS) and on glass. Data are expressed as mean \pm SD. The statistical significance $(p<0.05)$ is specified above the columns compared to the samples of the same treatment. * vs. Glass; \# vs. PS and Glass, "all" vs. all other samples. 
on larger nanotubes, with their diameter typically in the range from 20 to $80 \mathrm{~nm}$ (Filova et al., 2015). In a similar study on Ti modified with $\mathrm{TiO}_{2}$ nanotubes (Voltrova et al., 2019), $\mathrm{TiO}_{2}$ nanotubes $66 \pm 14 \mathrm{~nm}$ in diameter supported mostly the production of vinculin in Saos- 2 cells, while nanotubes $43 \pm 9 \mathrm{~nm}$ in diameter supported the production of talin in Saos-2 osteoblasts.

$\mathrm{Cr}$ is an electrically conductive element. The study of Khlusov et al. (2018) proved that surface nanoroughness and microroughness produce an electrical charge. Concurrently, sharp structures that are more homogeneous in size create a stronger electrical field than structures that are more variable in size. A negative charge was localised predominantly in the sockets, and a positive charge was localised in the nanorelief peaks. The presence of a negative charge supported osteogenic differentiation of human stromal cells. Simultaneously, in the present study, XPS proved the presence of $\mathrm{C}-\mathrm{O}, \mathrm{C}=\mathrm{O}$ groups from 4.8 at. $\%$ for pure DLC, to a maximum value of 12.2 at.\% at 7.3 and 7.7 at.\% of Cr (Jelinek et al., 2016b). Oxygen-based groups are negatively charged, and this may also contribute to the positive effect on cell adhesion of samples with a higher $\mathrm{Cr}$ content. In previous experiments, the zeta potential was also measured on Cr-doped DLC samples. However, similar potentials of pure samples and Cr-doped DLC were observed. The DLC and Cr-doped DLC zeta potential values were negative for $\mathrm{pH}$ values higher than 4.0, and were positive for a lower $\mathrm{pH}$ (Jelinek et al., 2014).

The hMSCs had lower metabolic activity on DLC doped with 0.9 at. $\%$ of $\mathrm{Cr}$ (sample 84 ) on day 1, and on the samples on DLC doped with 7.7 at.\% of $\mathrm{Cr}$ (sample 90) on day 3 than on PS. Similarly, reduced cell densities of hMSCs were obtained on DLC with both 3.7 and 7.3 at.\% of $\mathrm{Cr}$ than on DLC with 0.9 at.\% of $\mathrm{Cr}$ and 1.8 at.\% of $\mathrm{Cr}$ and with the control glass on day 3 (Jelinek et al., 2017). In another study, Saos2 cells also showed reduced cell density on DLC doped with 0.9 and 7.3 at.\% of $\mathrm{Cr}$ on day 3 (Jelinek et al. 2016b).

From day 7, the metabolic activity of hMSCs was either similar to the control samples (days 7 and 21 ), or it was even higher on samples 82, 86, 88, 90 on day 14. Similarly, on day 7 , the cell densities of hMSCs were similar on all samples (Jelinek et al., 2017). In the study with Saos-2, the density of Saos2 cells on DLC and on Cr-doped DLC increased to the values on the control Gl or PS on day 7 (Jelinek et al., 2016b). Interestingly, on day 7, Saos-2 cells reached higher densities on DLC doped with higher concentrations of $\mathrm{Cr}$, i.e. from 7.7 to 10 at.\% of $\mathrm{Cr}$ (Jelinek et al., 2016b), while in the present study, the metabolic activity of hMSCs, an indicator of cell number, remained similar to the other tested samples. A possible explanation for this different response of Saos-2 cells and hMSCs is a higher sensitivity of hMSCs (which are primocultured cells) to various chemical, physical, topographical and mechanical properties of the material.

The cytotoxic effect of $\mathrm{Cr}$ is associated with the presence of $\mathrm{Cr}^{6+}$. Very low $\mathrm{Cr}^{6+}$ levels of 0.6 at.\% were found on sample 88 and 1.1 at.\% were found on sample 86 from the overall $\mathrm{Cr} 2 \mathrm{p} 3 / 2$ peak area (Jelinek et al., 2016b). On the samples with 7.3 and 7.7 at. \% Cr., chromium carbide is also formed during magnetron sputtering (Jelinek et al., 2016b). Cr can mainly be released from chromium carbide when this compound is exposed to the acidic gastric fluid, and the release is about $0.00002 \mu \mathrm{g} / \mathrm{cm}^{2} / \mathrm{h}$ (Jiang et al., 2012). In the current study, the release of $\mathrm{Cr}$ into the cell culture media was not detected by 2 independent methods, i.e. EDS and AAS. However, some interaction between $\mathrm{Cr}$ and the cells on the cellmaterial interface cannot be excluded.

Another explanation for the slightly lesser growth of hMSCs on DLC-based samples on day 1 (sample 84 ), and on day 3 (samples 90) is the relatively high hydrophobicity of the DLC samples, which increased with higher $\mathrm{Cr}$ content from $79.9^{\circ}$ on pure DLC to $101.8^{\circ}$ on the sample with 7.7 at.\% of $\mathrm{Cr}$, and was accompanied by a decrease in free surface energy (from $34.4 \mathrm{~J} / \mathrm{m}^{2}$ to $28.3 \mathrm{~J} / \mathrm{m}^{2}$ ) (Jelinek et al., 2017). On hydrophobic materials, the cell adhesion-mediating proteins are adsorbed in a denatured and rigid form, which is a limiting factor for the cell adhesion, spreading and further proliferation of cells (for a review, see Vandrovcova and Bacakova 2011).

A rapid onset of osteogenic differentiation is crucial for the osseointegration of an implant and for bone defect healing. RUNX2 is an early transcription factor involved in the differentiation of stem cells towards osteoblasts, its presence is temporary and, in more mature osteoblasts, RUNX2 is downregulated (Bruderer et al., 2014). The fastest and the highest RUNX2 expression was found in cells on samples 90, 82 and 84. RUNX2 gene expression decreased on all samples on day 21 . This decrease can be explained by progressive maturation of the cells, where the levels of early differentiation markers can be downregulated. Similarly, the metabolic activity of the cells on samples 84 and 90 decreased on day 1 and 3, respectively. These findings are in accordance with a study by Stiehler et al. (2008), describing lower adhesion and proliferation together with higher osteogenic differentiation of hMSCs on pure $\mathrm{Cr}$ surfaces than on Ti and Ta surfaces.

Type I collagen, ALP, and osteocalcin are early, mid-term, and late markers of osteogenic cell differentiation, respectively. Increasing gene expression of early and mid-term markers (RUNX2, type I collagen, and ALP) was observed on all samples from day 5 to day 14 . The protein levels of type I collagen and osteocalcin reached the highest values on sample 90 (7.7 at.\% of $\mathrm{Cr}$, day 7$)$ and on sample 84 ( 0.9 at.\% of $\mathrm{Cr}$, day 14$)$. Interestingly, higher levels of osteogenic markers were obtained mainly on samples with no $\mathrm{Cr}$ content (pure DLC) 
or with a low $\mathrm{Cr}$ content $(0.9$ at. $\%$ of $\mathrm{Cr}$ ), but also on sample 90 (7.7 at.\% of Cr). Similarly, in an earlier study, performed on Saos-2 cells in cultures on Crdoped DLC layers, the samples without $\mathrm{Cr}$ or with lower concentrations of $\mathrm{Cr}$ (0.9 and 1.8 at.\%), which did not increase the cell adhesion and proliferation, supported osteogenic cell differentiation, manifested by increased expression of type I collagen and ALP at the mRNA and protein level (Filova et al., 2017). Based on the analyses of early, mid-term, and late osteogenic markers, the osteogenic differentiation rate of hMSCs was higher on sample 84 (0.9 at.\% Cr), as manifested by higher type I collagen expression and synthesis, osteocalcin synthesis, ALP activity, and on sample 90 (7.7 at.\% Cr), as manifested by higher expression of RUNX2, type I collagen and ALP, and by increased type I collagen and osteocalcin synthesis.

The variable onset and levels of osteogenic cell differentiation on $\mathrm{Cr}$-doped DLC, especially on samples with a higher $\mathrm{Cr}$ content, can also be explained by differences in the surface roughness and topography of these samples, which has already been discussed in the section on cell adhesion. Samples with a higher $\mathrm{Cr}$ content displayed a greater number of nanoscale surface irregularities, while pure DLC and DLC with a lower Cr content were rather flat, with sporadic irregularities (Filova et al., 2017). It is believed that surfaces with nanoscale irregularities better mimic the nanoarchitecture of the native extracellular matrix (ECM) than conventional flat surfaces. For example, in the study of Voltrova et al. (2019) on $\mathrm{TiO}_{2}$ modified with nanotubes, osteocalcin production by Saos-2 cells was the highest on smooth $\mathrm{TiO}_{2}$ and also on the smallest nanotubes, which were $24 \pm 5 \mathrm{~nm}$ in diameter. In a previous study, the production of type I collagen, alkaline phosphatase, osteopontin and osteocalcin was higher on nanotubes with a smaller diameter (Filova et al., 2015), typically in the range from 10 to $30 \mathrm{~nm}$ or from 20 to $70 \mathrm{~nm}$. Similarly to the improved cell adhesion, the improved osteogenic cell differentiation is also attributed to the adsorption of ECM molecules from biological fluids (including cell culture media) in a more physiological geometric conformation, which supports binding between specific bioactive sites in these molecules and cell adhesion receptors. Moreover, nanostructured surfaces adsorb more vitronectin, which is preferentially recognised and bound by osteoblasts (for a review, see (Vandrovcova and Bacakova, 2011).

$\mathrm{Cr}$ in various compounds and forms is known to support potential antimicrobial activity (Bazrafshan et al., 2018; Paez et al., 2013). The DLC layers presented here form a nanotopographic structure, which can be observed by AFM scans and are also hydrophobic (Filova et al., 2017). Although the mechanism by which nanostructures (e.g. nanopillars, nanowires, nanoneedles or nanocolumns) kill bacteria is still not completely clear, damage to the bacteria cell wall or inhibition of movement seem to be potential explanations for the antibacterial activity (Mas-Moruno et al., 2019). In an earlier study, the antimicrobial properties of Cr-doped samples were evaluated with Pseudomonas aeruginosa and Staphylococcus aureus, but no antimicrobial properties against these two microbial strains were observed (Jelinek et al., 2015).

For applications in bone tissue engineering, a heavy mechanical load is expected, and good adhesion of the layer to the substrate is required. The adhesion of DLC layers about $800 \mathrm{~nm}$ in thickness onto Ti6Al4V and CoCrMo alloys was tested with the use of scratching, with loading in the range from 1 to $30 \mathrm{~N}$. The values of critical loads (edge spallation and complete spallation) through the track were $7.9 \mathrm{~N}$ and 14.0-15.2 N for pure DLC, and 10.7 N and 17.6-19.0 N for 7.1 at. $\%$ of $\mathrm{Cr}$ on Ti6Al4V. For CoCrMo, the values of the critical load for edge spallation and complete spallation were $10.9 \mathrm{~N}$ and $20.0 \mathrm{~N}$ for pure DLC and 19.0-20.0 $\mathrm{N}$ and 25.2 $\mathrm{N}$ for DLC with 7.1 at.\% of $\mathrm{Cr}$ (Jelinek et al., 2015).

\section{Cell immune activation and cytokine production}

When macrophages, including cell lines of macrophage-like cells, come into contact with artificial materials, they adhere and spread, and then they can be activated (Ball et al., 2004). Activated macrophages produce a number of inflammatory mediators and ROS. In the current study, RAW 264.7 cells cultured in the medium with LPS showed slower proliferation, greater spreading (Fig. 8), the formation of vesicles in their cytoplasm, and increased production of 29 cytokines. However, such a response of RAW 2674.7 cells was very limited on DLC samples. The screening test showed that MIP-1 $\beta$ was produced by RAW 264.7 cells on DLC samples at slightly higher concentrations. Macrophage inflammatory protein $1 \beta$ (MIP- $1 \beta$, MIP- $1 b$, CCL4) is a chemotactic cytokine, expressed in various cells, e.g. in T-cells, B-cells, and monocytes after they have been stimulated by a mitogen or antigen. Both MIP- $1 \alpha$ and MIP-1 $\beta$ play a role in modulating immune responses (Bystry et al., 2001; Chang and Chen, 2016). The other cytokines, i.e. IL-12p40, IL-12p70, IL-1 $\alpha$, IL-1 $\beta$, IP-10, MIP-1 $\alpha$, MIP-1 $\delta$, RANTES, sTNFRII, TGF- $\beta 1$, Eotaxin-1, Eotaxin-2, IL-3, M-CSF, TNF- $\beta$, ICAM-1, and I-309 were produced at lower concentrations in the medium.

Both carbon and $\mathrm{Cr}$ might contribute to immune stimulation of the cells on the samples. In an in vitro study, J774A.1 macrophages were cultured with tetrahedral amorphous carbon sample (ta-C) films, polyurethane-coated (PU-coated) stainless steel and pure stainless steel (Ball et al., 2004). The production of hydrogen peroxide, i.e. an inflammatory mediator of macrophages, was significantly greater on tetrahedral amorphous carbon, on stainless steel, and on PU-coated stainless steel than on tissue culture polystyrene. In a study by Boyles et al. (2015), carbon in the form of carbon nanotubes was evaluated in vitro with mouse J774A.1 macrophage and human 
monocytic monomac-6 (MM6) cell lines. Long, high iron/low crystallinity carbon nanotubes stimulated J774A.1 macrophages to release MCP-1 at 24 and $48 \mathrm{~h}$ at particle concentrations from 7.5 to $31 \mu \mathrm{g} / \mathrm{mL}$, but there were no changes in the levels of IL- $1 \beta$, IL- 6 , or IL-10. TNF- $\alpha$ production by J774A.1 macrophages was increased after 4,24 and $48 \mathrm{~h}$, and TGF- $\beta 1$ production was increased after $48 \mathrm{~h}$ of culture with carbon nanotubes. MM6 cells cultured with carbon nanotubes increased the secretion of MCP-1 at 4, 24 and $48 \mathrm{~h}$ (Boyles et al., 2015).

However, some studies performed on carbonbased materials have not shown any immune response of cells and tissues. For example, stainless steel disks coated with fluorinated diamond-like carbon were implanted subcutaneously into rats. Markers of inflammation, such as IL- $1 \beta$ and TNF- $\alpha$, measured in the blood, were below the detection limit on days 3 and 7 after implantation (Hasebe et al., 2006).

The toxicity of metallic implants may be direct, occurring on the interface between the tissue and the material, or may be mediated by ions released from the implant. Moreover, the toxicity, including undesirable immune activation and inflammatory responses, always depends on the concentration of the toxic compound. Barlow et al. (2017) investigated normal metal ion levels after total hip arthroplasty. The concentration of $\mathrm{Cr}$ in the serum of healthy people was lower than $0.26 \mu \mathrm{g} / \mathrm{L}$. The measurements of serum levels of ions after implantation of 4 groups of implants, i.e. ceramic-on-ceramic, ceramicon-polyethylene, dual mobility and metal-onpolyethylene, showed that the $\mathrm{Cr}$ ion concentration was as follows: ceramic-on-ceramic: $0.5 \pm 0.0 \mu \mathrm{g} / \mathrm{L}$, ceramic-on-polyethylene: $0.72 \pm 0.54 \mu \mathrm{g} / \mathrm{L}$, dual mobility: $0.61 \pm 0.26 \mu \mathrm{g} / \mathrm{L}$, and metal-on-polyethylene: $0.74 \pm 0.47 \mu \mathrm{g} / \mathrm{L}$ (Barlow et al., 2017).

In an attempt to investigate the potential immunogenic effect of $\mathrm{Cr}$, the $\mathrm{Cr}$ release from the materials into the culture medium was assessed. No detectable concentration of released $\mathrm{Cr}$ ions was found in the culture medium.

$\mathrm{Cr}$ in high doses, or after long-term exposure, can cause cytotoxic and genotoxic reactions affecting the immune system. $\mathrm{Cr}$ induces hypersensitivity and is a common skin sensitiser. Hexavalent $\mathrm{Cr}$ enhances the production of ROS, causing damage to DNA and oxidative deterioration of lipids, leading to oxidative stress. This is followed by enhanced production of superoxide anions and hydroxyl radicals, increased lipid peroxidation and genomic DNA fragmentation, modulation of intracellular oxidised states, activation of protein kinase $\mathrm{C}$, apoptotic cell death, and altered gene expression (Shrivastava et al., 2002). Human peripheral $\mathrm{T}$ lymphocytes cultured in vitro in the presence of a CoCrMo disc had a slower rate of proliferation (Faleiro et al., 1996; Shrivastava et al., 2002). $\mathrm{Cr}^{6+}$ ions have been observed to stimulate apoptosis in various cell types, such as fibroblasts (Carlisle et al., 2000), lymphocytes (Akbar et al., 2011;
Vasant et al., 2001), and macrophages (Kwon et al., 2009). In the current study, the percentage of $\mathrm{Cr}^{6+}$ in the DLC films varied between 0.6 and $1.1 \%$ of the total $\mathrm{Cr}$ content, and the total amount of $\mathrm{Cr}$, i.e. $\mathrm{Cr}^{0}$, $\mathrm{CrC}, \mathrm{Cr}_{2} \mathrm{O}_{3^{\prime}} \mathrm{Cr}(\mathrm{OH})_{3}$ and $\mathrm{Cr}^{6+}$ was $0.9-7.7 \%$ (Jelinek et al., 2016b).

\section{Apoptosis}

Four markers of apoptosis from the BCL family were evaluated, i.e. BCL-XL, Bax, Bim and Bid. Anti-apoptotic BCL-2 protein BCL-XL is localised in cytosol, and it prevents the aggregation of proapoptotic BH123 proteins. Bax protein, a member of the pro-apoptotic $\mathrm{BH} 123$ proteins, is associated with the mitochondrial outer membrane. Upon apoptotic activation, Bax proteins bind to other Bax or BCL-2 molecules, interact with the mitochondrial membrane and induce opening of the mitochondrial voltagedependent anion channels through which cytochrome $\mathrm{C}$ is released. Bim and Bid are representatives of pro-apoptotic BH3-only proteins, which respond to apoptotic stimuli and inhibit anti-apoptotic BCL proteins (for a review, see (Deng, 2017)).

Osteoblast-like Saos-2 cells were employed for previous experiments, where the samples which contained a higher amount of $\mathrm{Cr}$ supported cell growth (Filova et al., 2017; Jelinek et al., 2016b). Saos- 2 cells are, however, of tumour origin. They lack p53 protein; thus, they are not the ideal model for studying apoptosis, despite the fact that they can undergo apoptosis through the mitochondrial pathway (Kovacs et al., 2016). This was confirmed in the current study by measuring apoptotic markers using qPCR and annexin V staining. However, the Saos-2 cells on the Cr-doped DLC samples did not respond systematically and conclusively. For this reason, an investigation of apoptosis with NHDFs (i.e. a primary culture of fibroblasts) was also included. NHDFs are cells of mesenchymal origin which are present in various tissues. They are also important because of their involvement in healing processes. In the initial part of the intramembranous bone healing process, fibroblasts are responsible for extracellular matrix synthesis (mainly collagen synthesis) prior to proper osteoblast differentiation and bone formation (Vieira et al., 2015). Moreover, some fibroblast growth factors (namely FGF2, FGF9 and FGF18) play a very important role in the bone healing process (Charoenlarp et al., 2017; Schmid et al., 2009; Yun et al., 2010).

In comparison with Saos-2, NHDFs showed upregulation in Bax and Bim genes, depending on the $\mathrm{Cr}$ content (without the addition of camptothecin). This finding is in accordance with the study by Fan et al. (2012), in which mouse hepatoma Hepa-1 cells grown in the presence of $0.25 \mu \mathrm{mol} / \mathrm{L} \mathrm{K}_{2} \mathrm{CrO}_{4}$ for 5 passages upregulated the expression of $\mathrm{Bax}, \mathrm{Bid}, \mathrm{Bak}$ and BCL-2 (Fan et al., 2012). Moreover, in the current experiments, when camptothecin was added, the expression of Bax and Bim increased 4 times on PS. On samples with a higher $\mathrm{Cr}$ content, the increase in 
the expression of these markers was less apparent. This could be due to the effect of Cr itself; the cells on samples containing a higher $\mathrm{Cr}$ content were weaker, and an additional stressing stimulus probably caused them not to withstand such unfavourable conditions and to undergo necrosis. Thus, pro-apoptotic markers in cells on samples with higher $\mathrm{Cr}$ concentrations did not reach higher levels than on samples with a lower Cr content.

This conclusion is supported by a flow cytometry analysis of annexin V/PI. NHDF on samples with increasing $\mathrm{Cr}$ content also slightly increased the signal from annexin $\mathrm{V}$ and PI; the proportion of apoptotic and necrotic cells was mostly $1: 1$. In the case of Saos- 2 cells, the ratio of apoptotic to necrotic cells was shifted to $1: 2$ or $1: 3$. After the addition of camptothecin, the proportion of apoptotic and necrotic NHDF increased to $1: 2.5$ on DLC samples, and in Saos- 2 cells even to $1: 6$.

The effect of $\mathrm{Cr}^{6+}$ ions on human lymphocytes has been tested in vitro (Akbar et al., 2011). The exposure of lymphocytes to $10-100 \mu \mathrm{mol} / \mathrm{L} \mathrm{Cr}^{6+}$ caused an increase in the level of apoptosis in both resting and activated lymphocytes. In the current experiments, chromium was bound into the DLC films, and no free $\mathrm{Cr}$ was detected in the medium. Thus, the proapoptotic effect could be caused not only by the presence of $\mathrm{Cr}^{6+}$, but also by the hydrophobicity of the material and the different content of oxygen in the tested materials (Filova et al., 2017; Jelinek et al., 2015; Jelinek et al., 2017; Jelinek et al., 2016b). A higher cell death rate of NHDF on samples with a higher $\mathrm{Cr}$ content is in accordance with a lower NHDF cell number on these samples, and also with lower metabolic activity in hMSC cells on these samples on day 3, although these cells started their osteogenic differentiation earlier.

\section{Clinical relevance}

DLC layers and Cr-doped DLC have excellent mechanical, physical, chemical, and biological properties, which predetermine them to be excellent materials for coatings of metallic bone implants, dental implants, or metallic parts of cardiovascular prostheses (Roy and Lee, 2007). For clinical use of artificial materials, it is desirable to evaluate their biocompatibility and some additional aspects of their interaction with the human body. This study has investigated a wide range of cell-material interactions, which involve cell viability/proliferation, differentiation, immune activation and the effect on apoptosis when specific cell types with an adequate response in individual parameters are used. The results of the in vitro study on different doping rates of DLC with Cr has helped the selection of DLC with a suitable $\mathrm{Cr}$ content that will stimulate a desirable cell response, while minimising potential side-effects or toxic effects, e.g. apoptosis. Chemical optimisation in turn leads to better implant osseointegration, and to better wound healing in patients.

\section{Conclusions}

In the study presented here, diamond-like carbon layers doped with $0,0.9,1.8,7.3$ and 7.7 at.\% $\mathrm{Cr}$ have been prepared.

On all DLC-based samples, the hMSCs differentiated towards osteoblasts. The osteogenic differentiation rate was higher on sample 84 (0.9 at.\% Cr) and on sample 90 (7.7 at.\% Cr).

Both Raw 264.7 cell spreading and their cytokine production while growing on Cr-doped DLC surfaces proved inconsiderable immune activation of RAW 264.7 cells on all samples.

Cr-doped DLC layers supported the production of pro-apoptotic markers proportionally to the $\mathrm{Cr}$ content in NHDFs, but not in Saos-2 cells.

In terms of the biological properties of the $\mathrm{Cr}$ doped DLC layers, sample 84 with 0.9 at.\% Cr seems to be the most suitable for biomedical applications.

\section{Acknowledgements}

This study was supported by the Grant Agency of the Czech Republic (grants No. GA-15-05864S and 2001570S). Further support was provided by BIOCEV - "Biotechnology and Biomedicine Centre of the Academy of Sciences and Charles University" (project CZ.1.05/1.1.00/02.0109), funded by the European Regional Development Fund, and by the National Programme for Sustainability II (grant LQ 1604). Mr. Robin Healey (Czech Technical University, Prague) is gratefully acknowledged for his language revision of the manuscript. Zuzana Jiraskova Zakostelska, Ph.D. is gratefully acknowledged for her help with quantification of RayBio ${ }^{\mathrm{TM}}$ Human Cytokine Array.

\section{References}

Akbar M, Brewer JM, Grant MH (2011) Effect of chromium and cobalt ions on primary human lymphocytes in vitro. J Immunotoxicol 8: 140-149.

Alanazi A, Nojiri C, Kido T, Noguchi T, Ohgoe Y, Matsuda T, Hirakuri K, Funakubo A, Sakai K, Fukui Y (2000a) Engineering analysis of diamond-like carbon coated polymeric materials for biomedical applications. Artif Organs 24: 624-627.

Alanazi A, Nojiri C, Noguchi T, Kido T, Komatsu Y, Hirakuri K, Funakubo A, Sakai K, Fukui Y (2000b) Improved blood compatibility of DLC coated polymeric material. ASAIO J 46: 440-443.

Allen M, Myer B, Rushton N (2001) In vitro and in vivo investigations into the biocompatibility of diamond-like carbon (DLC) coatings for orthopedic applications. J Biomed Mater Res 58: 319-328.

Angelliaume A, Ferrero E, Mazda K, Le Hanneur M, Accabled F, de Gauzy JS, Ilharreborde B (2017) Titanium vs. cobalt chromium: what is the best rod material to enhance adolescent idiopathic scoliosis 
correction with sublaminar bands? Eur Spine J 26: 1732-1738.

Asgharpour F, Moghadamnia AA, Motallebnejad M, Nouri HR (2019) Propolis attenuates lipopolysaccharide-induced inflammatory responses through intracellular ROS and NO levels along with downregulation of IL-1 beta and IL-6 expressions in murine RAW 264.7 macrophages. J Food Biochem 43: e12926. DOI: 10.1111/jfbc.12926.

Ball M, O'Brien A, Dolan F, Abbas G, McLaughlin JA (2004) Macrophage responses to vascular stent coatings. J Biomed Mater Res A 70: 380-390.

Barlow BT, Ortiz PA, Boles JW, Lee YY, Padgett DE, Westrich GH (2017) What are normal metal ion levels after total hip arthroplasty? A serologic analysis of four bearing surfaces. J Arthroplasty 32: 1535-1542.

Bazrafshan AA, Hajati S, Ghaedi M, Asfaram A (2018) Synthesis and characterization of antibacterial chromium iron oxide nanoparticle-loaded activated carbon for ultrasound-assisted wastewater treatment. Appl Organomet Chem 32: e3981. DOI 10.1002/ aoc.3981.

Boyles MSP, Young L, Brown DM, MacCalman L, Cowie H, Moisala A, Smail F, Smith PJW, Proudfoot L, Windle AH, Stone V (2015) Multi-walled carbon nanotube induced frustrated phagocytosis, cytotoxicity and pro-inflammatory conditions in macrophages are length dependent and greater than that of asbestos. Toxicol In Vitro 29: 1513-1528.

Bruderer M, Richards RG, Alini M, Stoddart MJ (2014) Role and regulation of RUNX2 in osteogenesis. Eur Cell Mater 28: 269-286.

Bystry RS, Aluvihare V, Welch KA, Kallikourdis M, Betz AG (2001) B cells and professional APCs recruit regulatory T cells via CCL4. Nat Immunol 2: 1126-1132.

Carlisle DL, Pritchard DE, Singh J, Patierno SR (2000) Chromium(VI) induces p53-dependent apoptosis in diploid human lung and mouse dermal fibroblasts. Mol Carcinog 28: 111-118.

Chang CH, Lin JS, Roberts WE (2019) Failure rates for stainless steel versus titanium alloy infrazygomatic crest bone screws: A single-center, randomized double-blind clinical trial. Angle Orthod 89: 40-46.

Chang TT, Chen JW (2016) Emerging role of chemokine CC motif ligand 4 related mechanisms in diabetes mellitus and cardiovascular disease: friends or foes? Cardiovasc Diabetol 15: 117. DOI: 10.1186/ s12933-016-0439-9.

Charoenlarp P, Rajendran AK, Iseki S (2017) Role of fibroblast growth factors in bone regeneration. Inflamm Regen 37: 10. DOI: 10.1186/s41232-017-00438.

Chen QZ, Thouas GA (2015) Metallic implant biomaterials. Mater Sci Eng R Rep 87: 1-57.

Dai W, Wu GS, Wang AY (2010) Preparation, characterization and properties of $\mathrm{Cr}$-incorporated DLC films on magnesium alloy. Diam Relat Mater 19: 1307-1315.

Dayan AD, Paine AJ (2001) Mechanisms of chromium toxicity, carcinogenicity and allergenicity: review of the literature from 1985 to 2000 . Hum Exp Toxicol 20: 439-451.

Deng J (2017) How to unleash mitochondrial apoptotic blockades to kill cancers? Acta Pharm Sin B 7: 18-26.

Faleiro C, Godinho I, Reus U, deSousa M (1996) Cobalt-chromium-molybdenum but not titanium6aluminium-4vanadium alloy discs inhibit human $\mathrm{T}$ cell activation in vitro. Biometals 9: 321-326.

Fan YX, Ovesen JL, Puga A (2012) Long-term exposure to hexavalent chromium inhibits expression of tumor suppressor genes in cultured cells and in mice. J Trace Elem Med Biol 26: 188-191.

Filova E, Fojt J, Kryslova M, Moravec H, Joska L, Bacakova L (2015) The diameter of nanotubes formed on Ti-6Al-4V alloy controls the adhesion and differentiation of Saos-2 cells. Int J Nanomedicine 10: 7145-7163.

Filova E, Vandrovcova M, Jelinek M, Zemek J, Houdkova J, Remsa J, Kocourek T, Stankova L, Bacakova L (2017) Adhesion and differentiation of Saos-2 osteoblast-like cells on chromium-doped diamond-like carbon coatings. J Mater Sci Mater Med 28: 17. DOI: 10.1007/s10856-016-5830-2.

Frank O, Heim M, Jakob M, Barbero A, Schafer D, Bendik I, Dick W, Heberer M, Martin I (2002) Real-time quantitative RT-PCR analysis of human bone marrow stromal cells during osteogenic differentiation in vitro. J Cell Biochem 85: 737-746.

Hasebe T, Shimada A, Suzuki T, Matsuoka Y, Saito T, Yohena S, Kamijo A, Shiraga N, Higuchi M, Kimura K, Yoshimura H, Kuribayashi S (2006) Fluorinated diamond-like carbon as antithrombogenic coating for blood-contacting devices. J Biomed Mater Res A 76: 86-94.

Jelinek M, Kocourek T, Zemek J, Miksovsky J, Kubinova S, Remsa J, Kopecek J, Jurek K (2015) Chromium-doped DLC for implants prepared by laser-magnetron deposition. Mater Sci Eng C Mater Biol Appl 46: 381-386.

Jelinek M, Pisarik P, Kocourek T, Zemek J, Kotzianova A, Jurek K, Miksovsky J, Luxbacher T (2014) Preliminary comparative study of laserprepared DLC and Cr-doped DLC for bacteria adhesion. Appl Phys A 116: 1437-1443.

Jelinek M, Zemek J, Kocourek T, Remsa J, Miksovsky J, Pisarik P, Jurek K, Tolde Z, Travnickova M, Vandrovcova M, Filova E (2016a) Dual laser deposition of Ti: DLC composite for implants. Laser Phys 26: 105605.

Jelinek M, Zemek J, Remsa J, Miksovsky J, Kocourek T, Pisarik P, Travnickova M, Filova E, Bacakova L (2017) Hybrid laser technology and doped biomaterials. Appl Surf Sci 417: 73-83.

Jelinek M, Zemek J, Vandrovcova M, Bacakova L, Kocourek T, Remsa J, Pisarik P (2016b) Bonding and bio-properties of hybrid laser/magnetron $\mathrm{Cr}$-enriched DLC layers. Mater Sci Eng C Mater Biol Appl 58: 1217-1224.

Jiang T, Wallinder IO, Herting G (2012) Chemical stability of chromium carbide and chromium nitride 
powders compared with chromium metal in synthetic biological solutions. ISRN Corrosion 2012(5): DOI: 10.5402/2012/379697.

Khlusov IA, Dekhtyar Y, Sharkeev YP, Pichugin VF, Khlusova MY, Polyaka N, Tjulkins F, Vendinya V, Legostaeva EV, Litvinova LS, Shupletsova VV, Khaziakhmatova OG, Yurova KA, Prosolov KA (2018) Nanoscale electrical potential and roughness of a calcium phosphate surface promotes the osteogenic phenotype of stromal cells. Materials 11: 978. DOI: 10.3390/ma11060978.

Kobayashi S, Ohgoe Y, Ozeki K, Hirakuri K, Aoki H (2007) Dissolution effect and cytotoxicity of diamond-like carbon coatings on orthodontic archwires. J Mater Sci Mater Med 18: 2263-2268.

Kopova I, Kronek J, Bacakova L, Fencl J (2019) A cytotoxicity and wear analysis of trapeziometacarpal total joint replacement implant consisting of DLCcoated Co-Cr-Mo alloy with the use of titanium gradient interlayer. Diam Relat Mater 97: 107456. DOI: 10.1016/j.diamond.2019.107456.

Kovacs D, Igaz N, Keskeny C, Belteky P, Toth T, Gaspar R, Madarasz D, Razga Z, Konya Z, Boros IM, Kiricsi M (2016) Silver nanoparticles defeat p53positive and p53-negative osteosarcoma cells by triggering mitochondrial stress and apoptosis. Sci Rep 6: 27902. DOI: 10.1038/srep27902.

Kwon YM, Xia Z, Glyn-Jones S, Beard D, Gill HS, Murray DW (2009) Dose-dependent cytotoxicity of clinically relevant cobalt nanoparticles and ions on macrophages in vitro. Biomed Mater 4: 025018. DOI: 10.1088/1748-6041/4/2/025018.

Leiber A, Graf B, Spring B, Rudner J, Kostlin N, Orlikowsky TW, Poets CF, Gille C (2014) Neonatal monocytes express antiapoptotic pattern of Bcl-2 proteins and show diminished apoptosis upon infection with Escherichia coli. Pediatr Res 76: 142-149.

Liao TT, Zhang TF, Li SS, Deng QY, Wu BJ, Zhang YZ, Zhou YJ, Guo YB, Leng YX, Huang N (2016) Biological responses of diamond-like carbon (DLC) films with different structures in biomedical application. Mater Sci Eng C Mater Biol Appl 69: 751-759.

Long M, Rack HJ (1998) Titanium alloys in total joint replacement - a materials science perspective. Biomaterials 19: 1621-1639.

Mas-Moruno C, Su B, Dalby MJ (2019) Multifunctional coatings and nanotopographies: toward cell instructive and antibacterial implants. Adv Healthc Mater 8: e1801103. DOI: 10.1002/ adhm.201801103.

McCall KD, Holliday D, Dickerson E, Wallace B, Schwartz AL, Schwartz C, Lewis CJ, Kohn LD, Schwartz FL (2010) Phenylmethimazole blocks palmitate-mediated induction of inflammatory cytokine pathways in 3T3L1 adipocytes and RAW 264.7 macrophages. J Endocrinol 207: 343-353.

Neophytou CM, Constantinou C, Papageorgis P, Constantinou AI (2014) D-alpha-tocopheryl polyethylene glycol succinate (TPGS) induces cell cycle arrest and apoptosis selectively in Survivin- overexpressing breast cancer cells. Biochem Pharmacol 89: 31-42.

Ozeki K, Masuzawa T, Hirakuri KK (2010) The wear properties and adhesion strength of the diamond-like carbon film coated on SUS, Ti and NiTi with plasma pre-treatment. Biomed Mater Eng 20: 21-35.

Paez PL, Bazan CM, Bongiovanni ME, Toneatto J, Albesa I, Becerra MC, Arguello GA (2013) Oxidative stress and antimicrobial activity of chromium(III) and ruthenium(II) complexes on Staphylococcus aureus and Escherichia coli. Biomed Res Int 2013: 906912. DOI: 10.1155/2013/906912.

Reichert JC, Nöth U, Berner A, Hutmacher DW (2016) Bone. In: Steinhoff G. (eds) Regenerative medicine - from protocol to patient, 5. Regenerative therapies II (pp. 280-304). Springer International Publishing AG Switzerland.

Reseland JE, Reppe S, Larsen AM, Berner HS, Reinholt FP, Gautvik KM, Slaby I, Lyngstadaas SP (2006) The effect of enamel matrix derivative on gene expression in osteoblasts. Eur J Oral Sci 114 Suppl 1: 205-211.

Rockwell GP, Lohstreter LB, Dahn JR (2012) Fibrinogen and albumin adsorption on titanium nanoroughness gradients. Colloids Surf B Biointerfaces 91: 90-96.

Rogers SD, Howie DW, Graves SE, Pearcy MJ, Haynes DR (1997) In vitro human monocyte response to wear particles of titanium alloy containing vanadium or niobium. J Bone Joint Surg Br 79: 311315.

Roy RK, Lee KR (2007) Biomedical applications of diamond-like carbon coatings: a review. J Biomed Mater Res B Appl Biomater 83: 72-84.

Schmid GJ, Kobayashi C, Sandell LJ, Ornitz DM (2009) Fibroblast growth factor expression during skeletal fracture healing in mice. Dev Dyn 238: 766774.

Schindelin J, Arganda-Carreras I, Frise E, Kaynig V, Longair M, Pietzsch T, Preibisch S, Rueden C, Saalfeld S, Schmid B, Tinevez J-Y, White DJ, Hartenstein V, Eliceiri K, Tomancak P, Cardona A(2012) Fiji: an open-source platform for biologicalimage analysis. Nat Methods 9: 676-682.

Shrivastava R, Upreti RK, Seth PK, Chaturvedi UC (2002) Effects of chromium on the immune system. FEMS Immunol Med Microbiol 34: 1-7.

Soininen A, Kaivosoja E, Sillat T, Virtanen S, Konttinen YT, Tiainen VM (2014) Osteogenic differentiation on DLC-PDMS-h surface. J Biomed Mater Res B Appl Biomater 102: 1462-1472.

Stiehler M, Lind M, Mygind T, Baatrup A, Dolatshahi-Pirouz A, Li H, Foss M, Besenbacher F, Kassem M, Bunger C (2008) Morphology, proliferation, and osteogenic differentiation of mesenchymal stem cells cultured on titanium, tantalum, and chromium surfaces. J Biomed Mater Res A 86: 448-458.

Tower SS (2010) Arthroprosthetic Cobaltism: Neurological and cardiac manifestations in two 
patients with metal-on-metal arthroplasty: a case report. J Bone Joint Surg Am 92: 2847-2851.

van Berlo D, Wilhelmi V, Boots AW, Hullmann M, Kuhlbusch TAJ, Bast A, Schins RPF, Albrecht C (2014) Apoptotic, inflammatory, and fibrogenic effects of two different types of multi-walled carbon nanotubes in mouse lung. Archives of Toxicology 88: 1725-1737.

Vandrovcova M, Bacakova L (2011) Adhesion, growth and differentiation of osteoblasts on surfacemodified materials developed for bone implants. Physiol Res 60: 403-417.

Vasant C, Balamurugan K, Rajaram R, Ramasami $\mathrm{T}$ (2001) Apoptosis of lymphocytes in the presence of $\mathrm{Cr}(\mathrm{V})$ complexes: role in $\mathrm{Cr}(\mathrm{VI})$-induced toxicity. Biochem Biophys Res Commun 285: 1354-1360.

Vieira AE, Repeke CE, Ferreira Junior Sde B, Colavite PM, Biguetti CC, Oliveira RC, Assis GF, Taga R, Trombone AP, Garlet GP (2015) Intramembranous bone healing process subsequent to tooth extraction in mice: micro-computed tomography, histomorphometric and molecular characterization. PLoS One 10: e0128021. DOI: 10.1371/journal.pone.0128021.

Voltrova B, Hybasek V, Blahnova V, Sepitka J, Lukasova V, Vocetkova K, Sovkova V, Matejka R, Fojt J, Joska L, Daniel M, Filova E (2019) Different diameters of titanium dioxide nanotubes modulate Saos-2 osteoblast-like cell adhesion and osteogenic differentiation and nanomechanical properties of the surface. RSC Adv. 9: 11341-11355.

Vyskocil A, Viau C (1999) Assessment of molybdenum toxicity in humans. J Appl Toxicol 19: 185-192.

Wang P, Wang X, Xu T, Liu WM, Zhang JY (2007) Comparing internal stress in diamond-like carbon films with different structure. Thin Solid Films 515: 6899-6903.

Wataha JC, O'Dell NL, Singh BB, Ghazi M, Whitford GM, Lockwood PE (2001) Relating nickelinduced tissue inflammation to nickel release in vivo. J Biomed Mater Res 58: 537-544.

Webster TJ, Ergun C, Doremus RH, Siegel RW, Bizios R (2000) Specific proteins mediate enhanced osteoblast adhesion on nanophase ceramics. J Biomed Mater Res 51: 475-483.

Wei Q, Sharma AK, Sankar J, Narayan J (1999) Mechanical properties of diamond-like carbon composite thin films prepared by pulsed laser deposition. Compos B Eng 30: 675-684.

Yokel RA (2000) The toxicology of aluminum in the brain: a review. Neurotoxicology 21: 813-828.

Yun YR, Won JE, Jeon E, Lee S, Kang W, Jo H, Jang JH, Shin US, Kim HW (2010) Fibroblast growth factors: biology, function, and application for tissue regeneration. J Tissue Eng 2010: 218142.

Zhang L, Ren XY, Alt E, Bai XW, Huang SY, Xu ZM, Lynch PM, Moyer MP, Wen XF, Wu XW (2010) Chemoprevention of colorectal cancer by targeting APC-deficient cells for apoptosis. Nature 464: 10581061.

\section{Discussion with Reviewer}

Keith Thompson: Could the authors speculate on how the chromium doping of the DLC coating may interact with fibrin following implantation in vivo?

Authors: Osseointegration is the functional connection between a bone tissue and an implant which can be influenced by many factors, including material properties of an implant. Proper osseointegration is considered to be a key process of cementless longterm and stable fixation of implants (Liu et al., 2020, additional reference). The process of osseointegration is characterised by the cascade of both cellular and extracellular events. Initially, the blood clot and fibrin clot are formed. Fibrin clot contains a plethora of signalling molecules (Anderson et al., 2008, additional reference). Subsequently, during bone healing, fibrin provides a temporary matrix enabling cell migration and attachment, followed by a process of angiogenesis and osteogenic differentiation (Bujoli et al., 2019, Liu et al., 2020, additional references). In general, DLC coatings possess good haemocompatibility properties (for a review, see: Alakoski et al., 2008, additional reference). Interestingly, doping the DLC with metals such as $\mathrm{Ti}$ or Ag can result in the formation of dense fibrin network and densely aggregated platelets on the material's surface (Andara et al., 2006, additional reference). In contrast, the platelets were only sporadically present on unalloyed DLC and no fibrin network was exhibited on this DLC coating in the same study (Andara et al., 2006, additional reference). In addition, doping the DLC coating with F can decrease the platelet covered area (Hasebe et al., 2007 , additional reference). The potential influence of $\mathrm{Cr}$ on platelet and leukocyte adhesion and activation, thrombin generation and fibrin formation has been reported in several studies (Gossart et al., 2019, Venter et al., 2017, Ollivier et al., 2016, additional references). Specifically, blood exposed to $\mathrm{Cr}$, under ex vivo conditions, can exhibit varied erythrocyte morphologies, activated platelets and thicker fibrin fibres than in a control group (Venter et al., 2017, additional reference). Moreover, pure $\mathrm{CoCr}$ alloys without any additional coating enable platelet adhesion and activation, leukocyte adhesion, increased thrombin generation and fibrin formation (Ollivier et al., 2016, Gossart et al., 2019, additional references). The platelet adhesion, thrombin generation and fibrin formation can therefore be modulated by the $\mathrm{Cr}$ presence. Nevertheless, there are also other material properties playing an important role in tissue-implant interaction. Roughness is one of the most crucial properties that strongly influence the fibrin clot formation; i.e. the greater surface roughness correlates with fibrin clot extension (Di Iorio et al., 2005, additional reference). Moreover, microroughness seems to be the crucial tool for better osseointegration and nanotopography is applied to better mimic the endogenous structure of bone (Additional reference: Gittens et al., 2014). 


\section{Additional References}

Alakoski E, Tiainen VM, Soininen A, Konttinen YT (2008) Load-bearing biomedical applications of diamond-like carbon coatings - current status. Open Orthop J 2: 43-50.

Anderson JM, Rodriguez A, Chang DT (2008) Foreign body reaction to biomaterials. Semin Immunol 20: 86-100.

Andara M, Agarwal A, Scholvin D, Gerhardt RA, Doraiswamy A, Jin C, Narayan RJ, Shih CC, Shih CM, Lin SJ, Su YY (2006) Hemocompatibility of diamondlike carbon-metal composite thin films. Diam Relat Mater 15: 1941-1948.

Bujoli B, Scimeca JC, Verron E (2019) Fibrin as a multipurpose physiological platform for bone tissue engineering and targeted delivery of bioactive compounds. Pharmaceutics 11: 556. DOI: 10.3390/ pharmaceutics11110556.

Di Iorio D, Traini T, Degidi M, Caputi S, Neugebauer J, Piattelli A (2005) Quantitative evaluation of the fibrin clot extension on different implant surfaces: an in vitro study. J Biomed Mater Res B Appl Biomater 74: 636-642.

Gittens RA, Olivares-Navarrete R, Schwartz Z, Boyan BD (2014) Implant osseointegration and the role of microroughness and nanostructures: lessons for spine implants. Acta Biomater 10: 3363-3371.

Gossart A, Letourneur D, Gand A, Regnault V, Mlouka MA, Cosette P, Pauthe E, Ollivier V,
Santerre JP (2019) Mitigation of monocyte driven thrombosis on cobalt chrome surfaces in contact with whole blood by thin film polar/hydrophobic/ionic polyurethane coatings. Biomaterials 217: 119306. DOI: 10.1016/j.biomaterials.2019.119306.

Hasebe T, Ishimaru T, Kamijo A, Yoshimoto Y, Yoshimura T, Yohena S, Kodama H, Hotta A, Takahashi K, Suzuki T (2007) Effects of surface roughness on anti-thrombogenicity of diamond-like carbon films. Diam Relat Mater 16: 1343-1348.

Liu Y, Rath B, Tingart M, Eschweiler J (2020) Role of implants surface modification in osseointegration: a systematic review. J Biomed Mater Res A 108: 470484.

Ollivier V, Roques C, Receveur N, Gratz M, Feldman L, Letourneur D, Gachet C, Mangin PH, Jandrot-Perrus M (2017) Bioreactivity of stent material: activation of platelets, coagulation, leukocytes and endothelial cell dysfunction in vitro. Platelets 28: 529-539.

Venter C, Oberholzer HM, Bester J, van Rooy MJ, Bester MJ (2017) Ultrastructural, confocal and viscoelastic characteristics of whole blood and plasma after exposure to cadmium and chromium alone and in combination: an ex vivo study. Cell Physiol Biochem 43: 1288-1300.

Editor's note: The Scientific Editor responsible for this paper was Martin Stoddart. 